Elsevier required licence: (C) $<2020>$. This manuscript version is made available under the CC-BY-NCND 4.0 license http://creativecommons.org/licenses/by-nc-nd/4.0/

The definitive publisher version is available online at

[https://www.sciencedirect.com/science/article/pii/S1385894720313784?via\%3Dihub] 


\section{Journal Pre-proofs}

Enhancing the Performance of Membrane Distillation and Ion-Exchange Manganese Oxide for Recovery of Water and Lithium from Seawater

Sharaniya Roobavannan, Saravanamuthu Vigneswaran, Gayathri Naidu

PII: S1385-8947(20)31378-4

DOI: https://doi.org/10.1016/j.cej.2020.125386

Reference: CEJ 125386

To appear in: Chemical Engineering Journal

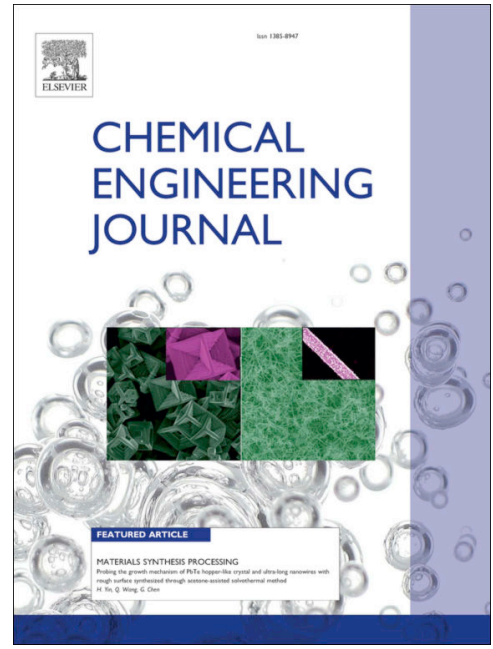

Received Date: $\quad 12$ February 2020

Revised Date: $\quad 1$ May 2020

Accepted Date: $\quad 4$ May 2020

Please cite this article as: S. Roobavannan, S. Vigneswaran, G. Naidu, Enhancing the Performance of Membrane Distillation and Ion-Exchange Manganese Oxide for Recovery of Water and Lithium from Seawater, Chemical Engineering Journal (2020), doi: https://doi.org/10.1016/j.cej.2020.125386

This is a PDF file of an article that has undergone enhancements after acceptance, such as the addition of a cover page and metadata, and formatting for readability, but it is not yet the definitive version of record. This version will undergo additional copyediting, typesetting and review before it is published in its final form, but we are providing this version to give early visibility of the article. Please note that, during the production process, errors may be discovered which could affect the content, and all legal disclaimers that apply to the journal pertain.

(C) 2020 Elsevier B.V. All rights reserved. 


\title{
Enhancing the Performance of Membrane Distillation and Ion-Exchange Manganese Oxide for Recovery of Water and Lithium from Seawater
}

\author{
Sharaniya Roobavannan ${ }^{\mathrm{a}, 1}$, Saravanamuthu Vigneswaran ${ }^{\mathrm{a},{ }^{*}}$,Gayathri Naidu ${ }^{\mathrm{a},{ }^{*}}$ \\ ${ }^{a}$ School of Civil and Environmental Engineering, University of Technology Sydney (UTS), City Campus, \\ Broadway, NSW 2007, Australia, \\ ${ }^{1}$ S. Roobavannan and G. Naidu contributed equally to this work \\ *Corresponding authors: Email: Saravanamuth.Vigneswaran@uts.edu.au (S. Vigneswaran); \\ Gayathri.Danasamy@uts.edu.au (G. Naidu)
}

\begin{abstract}
Recovering lithium (Li) from natural sources such as seawater is a sustainable alternative to meet its high demands. Li recovery from seawater must be enhanced to attain economic efficiency. In this work, the potential of enhancing Li recovery from seawater by acid treated manganese oxide ion sieve (HMO) is evaluated by increasing Li concentration in seawater using direct contact membrane distillation (DCMD) and reducing competitive ions. DCMD achieved enhanced water recovery upon pre-treatment with oxalic acid (88-91\%) compared to caustic soda ash (65-68\%) and without pre-treatment (47-51\%). Caustic soda ash required $\mathrm{Na}$ addition in alkaline condition for Ca removal, while, oxalic acid removed $\mathrm{Ca}$ in acidic condition without any inorganic ion addition. The low ion concentration in acidic condition upon oxalic acid pre-treatment enabled DCMD to concentrate seawater to high levels, increasing Li concentration by 7 times. In Li solution, HMO achieved a maximum adsorptive capacity (Langmuir Qmax) of $17.8 \mathrm{mg} / \mathrm{g}$ in alkaline condition. Multiple cycles of desorption and regeneration of HMO showed only 7-11\% decline of Li uptake and minimal Mn dissolution, which, established HMO's reuse capacity. Selective Li mechanism is attributed to H/Li
\end{abstract}


exchange as well as high negative surface charge of HMO. In seawater, Li uptake by HMO reduced by $44-46 \%$ due to $\mathrm{Mg}$. Seawater with minimal $\mathrm{Mg}$ was favourable for enhancing $\mathrm{Li}$ uptake by HMO. Seawater treatment in stages - divalent pretreament and concentrating seawater, followed by HMO, provided a favourable scenario for attaining high quality water, selective Li recovery, and other resources - $\mathrm{Ca}$ and $\mathrm{Mg}$.

\section{Keywords}

Lithium, Membrane Distillation, Manganese oxide ion sieve, Water Recovery, Seawater

\section{Introduction}

Seawater is a complex solution comprising of a vast variety of elements. Apart from major ions in high concentration such as $\mathrm{Na}, \mathrm{Mg}, \mathrm{Ca}$ and $\mathrm{K}$, seawater also contain valuable trace elements that are scare in mine ores such as $\mathrm{Rb}$ and economically important $\mathrm{Li}[1,2]$. The interest of recovering Li from natural sources is attributed to its rising demand as high energy storage battery $[1,3]$. Given the amount of seawater is extensive and inexhaustible, the total $\mathrm{Li}$ in seawater is projected to be much larger than that of mine ores. Globally, over $200 \mathrm{Gt}$ mass of Li could be extracted from seawater. Further, compared to Li extraction from mine ores (complex hydrometallurgical processes with high chemical usage), extraction of Li from seawater is less detrimental towards the environment $[1,4,5]$. Due to these factors, the recovery of valuable Li from seawater is becoming an attractive option.

A number of methods has been evaluated for $\mathrm{Li}$ recovery from seawater such as evaporation/precipitation, selective membrane processes, electrodialysis, electrochemical and ion exchange adsorption $[1,2,4,6]$. For instance, membrane technologies such as pressure 
driven nanofiltration, supported liquid membrane and electrically-driven membrane-based technologies namely electrodialysis and capacitive deionization with selective exchange membranes are being applied for $\mathrm{Li}$ extraction [6]. Positively charged nanofiltration membranes have been effective for selective $\mathrm{Li}$ to $\mathrm{Mg}$ separation from brine [7]. Likewise, supported liquid membrane with solvent exchange enables to attain selective Li extraction [8]. However, the main challenges of Li extraction by membrane process such as nanofiltration is the high fouling development during brine treatment while stability and solvent leakage remains challenges of liquid membranes. Comparatively ion exchange adsorption is widely adopted due to its capacity to selectively extract Li present in trace concentration from complex seawater solution at a relatively low cost with ease of operation for practical industrial application. Specifically, inorganic lithium manganese ion sieves synthesised from lithium manganese oxides (LMOs), such as $\mathrm{Li}_{1.6} \mathrm{Mn}_{1.6} \mathrm{O}_{4}, \mathrm{LiMn}_{2} \mathrm{O}_{4}$, and $\mathrm{Li}_{1.33} \mathrm{Mn}_{1.67} \mathrm{O}_{4}$, display excellent performance for selective uptake of $\mathrm{Li}$ from seawater [9-13]. The high selective Li capacity of LMOs is attributed to its unique topotatic $\mathrm{Li} / \mathrm{H}$ ion exchange characteristics that extract $\mathrm{Li}$ in $\mathrm{LMO}$ by ion exchange with $\mathrm{H}$ when treated in acidic solution, producing $\mathrm{H}$-form manganese ion sieves (HMO). As a consequence, HMO consists of pore sizes similar to that of Li ion compared to other ions in seawater, which allows for selective Li uptake. Li uptake from seawater and saline brine using various types of HMO has been reported by previous studies. For instance Wang et al [14] synthetized three types of HMO using furnace and hydrothermal method and reported the capacity of HMO to selectively extract Li from geothermal brine. In another study, Gu et al [15] used an improved solid state method to synthesis lithium ion sieve with titanium and achieved enhanced Li uptake from salt lake brine. Liu et al [16] used sol-gel and hydrothermal method to synthesize spinel manganese oxide ion sieve with one-dimensional nanowires for Li extraction from seawater. 
However, in spite of HMO's capacity for selective Li uptake in seawater, this ion exchange adsorption approach is unable to attain economic efficient Li recovery from seawater. One of the primary reasons for this is the low concentration range of $\mathrm{Li}(0.14-0.19 \mathrm{mg} / \mathrm{L})$ in seawater. It is well-established that the initial concentration of ions play a significant role in influencing the performance capacity of adsorbents $[12,17]$. Concentrating seawater, in effect, will enable to increase initial Li concentration, thereby, enhancing the capacity of HMO. Thus far, previous studies have evaluated this phenomena by spiking higher Li concentration in model solution as well as in mixed solutions such as seawater brine $[12,16,18]$. For instance, Tian et al [12] achieved $75 \%$ higher Li uptake with HMO by spiking the initial Li concentration in a model solution from $20 \mathrm{mg} / \mathrm{L}$ to $35 \mathrm{mg} / \mathrm{L}$. Compared to previous studies, for the first time, this study investigated the potential of increasing $\mathrm{Li}$ concentration in actual seawater by treating/concentrating seawater while simultaneously producing fresh water using membrane distillation (MD).

Membrane distillation (MD) offers the potential to concentrate seawater (in turn, increase Li concentration) while producing freshwater. As a thermal vapour pressure driven process using a hydrophobic membrane, MD is not significantly affected by high salinity. Hence, compared to seawater desalination with reverse osmosis, MD in principle, can achieve highly concentrated seawater while producing good quality fresh water. The potential of MD as an alternative seawater desalination treatment process has been successfully demonstrated by a number of researchers [19-21]. Although MD can effectively treat seawater, in thermal condition, inorganic membrane scaling, specifically, $\mathrm{CaSO}_{4}$ deposition onto the membrane, is a major phenomenon that compromises the capacity of MD to achieve high water recovery while concentrating seawater [22, 23]. Minimizing Ca content (seawater softening) is a practical approach to control $\mathrm{CaSO}_{4}$ scaling in MD. In line with this, $\mathrm{Li}$ et al [6] indicated the 
importance of minimizing membrane scaling and fouling development to enhance the efficiency of membrane processes such as nanofiltration and MD for treating and concentrating Li from brine.

A conventional chemical method adopted for water softening (divalent removal) is caustic soda ash addition [24-26]. A few MD studies for seawater brine treatment have demonstrated improved MD performance with caustic soda softened brine [24, 27, 28]. For instance, Sanmartino et al [24] demonstrated the capacity of MD to concentrate caustic soda ash softened seawater brine from $55 \mathrm{~g} / \mathrm{L}$ by up to $350 \mathrm{~g} / \mathrm{L}$. Comparatively, without caustic soda ash softening, seawater brine was only concentrated up to $153 \mathrm{~g} / \mathrm{L}$. Likewise, Ji, et al. [27] used caustic soda ash softening in seawater brine to reduce scaling and to obtain higher brine concentration levels in MD-crystallizer. Nevertheless, it is still a challenge for MD to achieve highly concentrated seawater levels with caustic soda ash softening. This is because $\mathrm{Ca}$ precipitation in caustic soda ash approach occur in alkaline condition, thereby, requiring the addition of sodium hydroxide to increase seawater $\mathrm{pH}$. The addition of sodium (from hydroxide and carbonate) increases ion concentration in seawater. Invariably, ion concentration effect becomes more prevalent, especially as MD attempts to continuously concentrate the seawater, resulting in permeate flux decline over time $[29,30]$. Further, the residues of hydroxide and carbonate in alkaline thermal condition, increases susceptibility towards scalant formation onto the membrane, which invariably compromises the capacity of MD to further concentrate seawater [31].

In comparison to caustic soda ash softening, organic polycarboxylic acids such as oxalic acid may offer an alternative approach to seawater softening without the addition of sodium. The high catalytic capacity of oxalic acid has been demonstrated for hydrolysing biomass [32], 
mineral surface dissolution [33], acidification for sewage sludge dewatering [34] and fermentation of algae [35]. In the field of hydrometallurgy, oxalic acid demonstrated superior scalant mitigation capacity compared to caustic soda ash, due to its capacity to selectively precipitate $\mathrm{Ca}$ without any additional ions (sodium/hydroxide/carbonate) introduced to the solution. Further, oxalic acid exhibits capacity for selective Ca removal in mixed solutions containing both $\mathrm{Ca}$ and $\mathrm{Mg}$ (Moldoveanu and Papangelakis, 2015). On this basis, oxalic acid could be suitable to attain selective Ca removal from seawater without introducing any additional ions, and thereby, minimizing scaling during MD process. Further, unlike the alkaline condition of caustic soda ash, the acidic condition with oxalic acid could be beneficial to increase induction time of saturated ion, in turn, delaying precipitation of ions [36]. The suitability of oxalic acid as a seawater pretreatment for scaling mitigation in MD is yet to be explored. For the first time, this study compares the effectiveness of caustic soda ash over oxalic acid as Ca removal method from seawater. Further, upon MD treatment, the capacity of oxalic acid treated seawater to retain Li mass with minimal losses through co-precipitation must be evaluated. Detailed investigation is necessary to establish these scenarios.

Hence, the aims of this study are to examine the performance of HMO for Li uptake from seawater and identify favourable conditions to enhance the capacity of HMO for selective Li uptake. For these reasons, firstly, the potential of DCMD to achieve high water recovery while increasing Li concentration in seawater upon chemical softening was evaluated. Specifically, the suitability of oxalic acid compared to caustic soda ash as a seawater chemical softening agent for mitigating scaling in DCMD was examined. Secondly, in order to understand the mechanisms of selective Li uptake of HMO and identify conditions that enhances its performance, detailed chemical and physical characteristics of HMO was analysed. Factors that influence $\mathrm{HMO}$ performance such as $\mathrm{pH}$, surface charge, time, equilibrium dose and 
concentration was evaluated. Further, the role of ion competition was examined by comparing HMO performance for selective Li uptake in original seawater and pretreated concentrated seawater. Lastly, desorption and regeneration of HMO was carried out to establish the reuse capacity of HMO. 


\section{Methodology}

\subsection{Materials}

\subsubsection{Chemicals and Solutions}

A model Li solution $(5.0 \mathrm{mg} / \mathrm{L})$ and real seawater were used to evaluate the performance of HMO for selective Li uptake. Seawater used in this study was collected from Sydney Institute of Marine Science, Chowder Bay, Australia. The characteristics of the seawater in presented in Table 1. The Li concentration in the model Li solution $(5.0 \mathrm{mg} / \mathrm{L})$ was substantially higher compared to that present in seawater $(0.2 \mathrm{mg} / \mathrm{L})$. Higher Li concentration was used to ensure consistent analytic interpretation at equilibrium condition; as well as to clearly demonstrate the mechanism trend of HMO towards selective Li uptake. Further, model solutions of Li with $\mathrm{Na}$, $\mathrm{Mg}$ and $\mathrm{Ca}$ were used to evaluate the effect of ions present in mixed constituents in seawater. Stock chemical ( $\mathrm{Na}, \mathrm{Mg}, \mathrm{Ca}$ and $\mathrm{Li}$ ) solutions were obtained by mixing respective chemical chloride salts $\left(\mathrm{NaCl}, \mathrm{MgCl}_{2}, \mathrm{CaCl}_{2}\right.$ and $\left.\mathrm{LiCl}\right)$ in deionised water (DI water). Analytical grade chemical salts obtained from Sigma-Aldrich (US) were used for preparing the chemical solutions.

Seawater and pretreated seawater (containing minimal Ca) were used for DCMD experiments to evaluate the influence of inorganic ions in membrane scaling and concentrate treatment. Divalent reduced seawater was achieved by chemical pre-treatment using oxalic acid and caustic soda ash.

Table 1 Key characteristics of seawater

\begin{tabular}{ll}
\hline Parameter & Value \\
\hline Turbidity & $0.3 \pm 0.2 \mathrm{NTU}$ \\
Total dissolved solids (TDS) & $35000 \mathrm{mg} / \mathrm{L}$
\end{tabular}




\begin{tabular}{ll}
\hline Parameter & Value \\
\hline Dissolved organic carbon (DOC) & $1.6 \pm 0.7 \mathrm{mg} / \mathrm{L}$ \\
$\mathrm{pH}$ & $8.0 \pm 0.3$ \\
Inorganic ions (mg/L) & \\
$\mathrm{Ca}$ & $416.81 \pm 0.40$ \\
$\mathrm{Mg}$ & $1414.80 \pm 1.60$ \\
$\mathrm{Na}$ & $11393.51 \pm 3.22$ \\
$\mathrm{~K}$ & $420.31 \pm 2.10$ \\
$\mathrm{Sr}$ & $7.85 \pm 0.71$ \\
$\mathrm{Li}$ & $0.18 \pm 0.02$ \\
$\mathrm{Rb}$ & $0.18 \pm 0.02$ \\
\hline
\end{tabular}

\subsubsection{Membrane}

The DCMD experiments (as described in Section 2.2.2) was carried out using polytetrafluoroethylene (PTFE) commercial hydrophobic membrane (General Electric, US). The membrane characteristics (thickness, porosity, pore size and contact angle) was 178-180 $\mu \mathrm{m}, 70-80 \%, 0.20-0.22 \mu \mathrm{m}$ and $138.6 \pm 2.7^{\circ}$ respectively, as described in our previous papers [37] and in the supplementary material.

\subsubsection{Nanoparticle}

Lithium manganese oxide (LMO) was used for Li extraction evaluation. The adsorbent was synthesized using solution of $\mathrm{LiOH}$ solution and $\mathrm{Mn}_{2} \mathrm{O}_{3}$ powder as described in Section 2.2.1. Analytical grade chemical salts obtained from Sigma-Aldrich (US) were used.

\subsection{Methods}




\subsubsection{Nanoparticle synthesis}

A hydrothermal process was used to synthesis lithium manganese oxide (LMO), based on the procedure of Chitrakar et al [9]. In brief, the synthesis was carried out by mixing $10 \mathrm{~g}$ of $\mathrm{Mn}_{2} \mathrm{O}_{3}$ with $\mathrm{LiOH}(4.0 \mathrm{M}, 200 \mathrm{~mL})$ solution. The solution was stirred homogenously for $6 \mathrm{~h}$ in room temperature $\left(24.0 \pm 0.5^{\circ} \mathrm{C}\right)$. Next, the solution was placed in a teflon-lined stainless autoclave hydrothermal reactor and heated at $120^{\circ} \mathrm{C}$ for $24 \mathrm{~h}$. Thereafter, the precipitate was centrifuged (3000 rpm) for 10 mins and filtered. The filtered residue was rinsed several times with DI water and oven dried at $50{ }^{\circ} \mathrm{C}$ for $12 \mathrm{~h}$. Next, the dried product was grounded with mortar and pestle and sieved (using Standard Testing Woven Wire Mesh Sieves) to obtained homogenous powder. The powder form LMO (2.0 g) was immersed in HCL (0.5 M, 2.0 L) and stirred (120 $\mathrm{rpm}$ ) for $24 \mathrm{~h}$ at room temperature. This step is to facilitate LMO delithiation ( $\mathrm{Li}$ to $\mathrm{H}$ exchange), producing acid manganese oxide (HMO). The final HMO was washed repetitively with DI water, vacuum filtered and thereafter, oven dried at $40{ }^{\circ} \mathrm{C}$ for $12 \mathrm{~h}$. The synthesized HMO was kept in an air tight container.

\subsubsection{Seawater chemical pre-treatment}

Seawater chemical pre-treatment was carried out using two different methods, oxalic acid and caustic soda ash method.

For the oxalic acid method, oxalic acid at different doses were added to $100 \mathrm{ml}$ seawater in beakers. The beakers were kept in suspension (120 rpm speed) for $24 \mathrm{~h}$ at room temperature. Thereafter, $\mathrm{Mg}$ precipitation was carried out by adding $\mathrm{NaOH}$ at varied $\mathrm{pH}(\mathrm{pH}$ 9-12). The beakers were placed in a shaker (120 rpm speed) for $48 \mathrm{~h}$. At the end of each step, seawater samples were filtered using a vacuum filter with glass microfiber filter (Filtech, Australia, 1.1 $\mu \mathrm{m}$ average pore size) to remove and separate the precipitated salts. For the caustic soda ash 
beaker method, different doses of $\mathrm{Na}_{2} \mathrm{CO}_{3}$ was added to seawater at varied $\mathrm{pH}$ from 9-12 using $\mathrm{NaOH}$. The beakers were kept suspended for $24 \mathrm{~h}$. Dissolved ion contents of the initial and final filtered seawater samples were measured to determine the $\mathrm{Ca}$ and $\mathrm{Mg}$ removal rate.

\subsubsection{Direct contact membrane distillation (DCMD)}

A lab scale DCMD was used to treat and concentrate seawater and pretreated seawater (Fig. 1). The lab scale DCMD was operated with a PTFE membrane (details provide in Section 2.1.2), placed in an acrylic membrane module with a length, width and channel depth of 8.10 $\mathrm{cm} \times 5.10 \mathrm{~cm} \times 0.23 \mathrm{~cm}$ respectively (total active membrane area of $40 \mathrm{~cm}^{2}$ ). DCMD was operated with a feed and permeate temperature of $55^{\circ} \mathrm{C}$ and $25{ }^{\circ} \mathrm{C}$ as discussed in our earlier work $[37,38]$. A $1.8 \mathrm{~L}$ volume of initial feed and permeate solution was used and the solutions were recirculated in counter-current mode at a flow rate of $0.5 \mathrm{~L} / \mathrm{min}$ (translating to a flow velocity of $0.08 \mathrm{~m} / \mathrm{s}$ ). Seawater was treated and concentrated with DCMD by up to $85 \%$ water recovery (corresponding to an initial feed volume decrease of $1.80 \mathrm{~L}$ to around $0.36 \mathrm{~L}$ ) or up to near-zero decline flux condition. The distillate/permeate production was presented as permeate flux ( $\left.\mathrm{L} \mathrm{m}^{-2} \mathrm{~h}^{-1}(\mathrm{LMH})\right)$ which was computed by permeate volume (L) increment ratio over membrane area $\left(\mathrm{m}^{2}\right)$ and operation duration $(\mathrm{h})$. Automated balance was used for capturing the mass changes of the permeate solution (DI water as initial permeate solution). In this study, the permeate flux was categorised as a function of the water recovery rate along with volume concentration factor (VCF). 


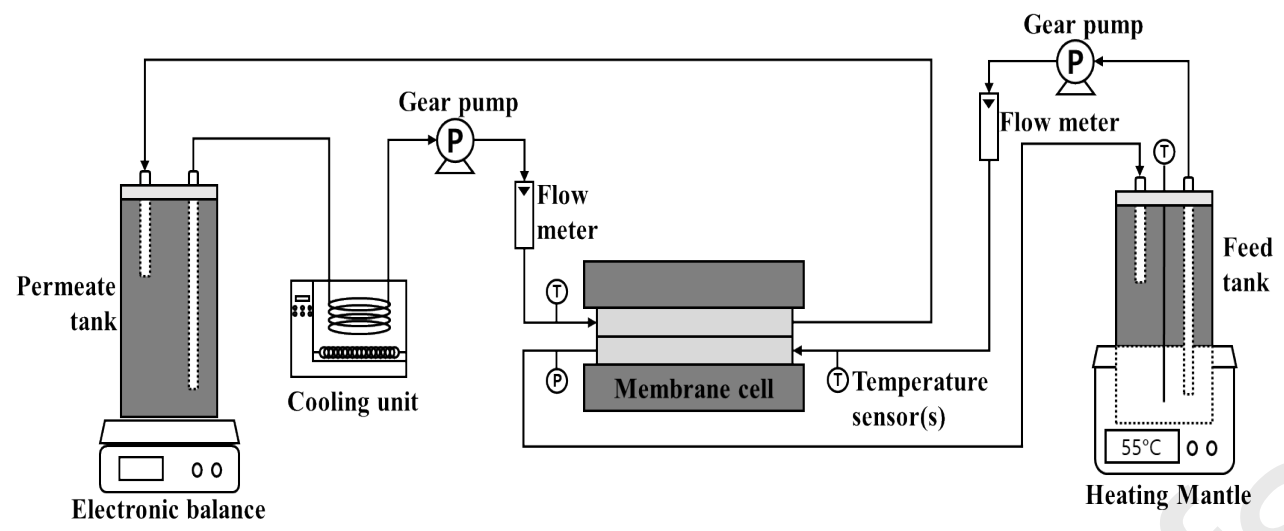

Fig. 1 Experimental setup of DCMD.

\subsubsection{Adsorbent experiments}

Adsorbent experiment were carried in batch beaker containing pre determined amount of HMO with $100 \mathrm{~mL}$ of solutions and kept suspended with mixing at $120 \mathrm{rpm}$. The initial and final ion concentrations was measured with inductively coupled plasma mass spectrometry (ICP-MS) (Agilent 4100). Test were replicated and the standard average were reported. The difference between replicates were less than $\pm 4 \%$.

\subsubsection{Influence of $\mathrm{pH}$}

Influence of $\mathrm{pH}$ on Li uptake at equilibrium was examined at base and acid settings. HMO, at a dose of $0.05 \mathrm{~g} / \mathrm{L}$ was placed in beakers with $5.0 \pm 0.5 \mathrm{mg} \mathrm{Li} / \mathrm{L}$ solution in the $\mathrm{pH}$ ranges of 2 to 12 . The beakers were stirred $(120 \mathrm{rpm})$ for $24 \mathrm{~h}$ in room temperature. Initial $\mathrm{pH}$ values were changed with a few drops of concentrated acid $(\mathrm{HCl})$ and base $(\mathrm{NaOH})$ solution. Measurement of the solutions initial $\mathrm{pH}\left(\mathrm{pH}_{\mathrm{in}}\right)$ and final/equilibrium $\mathrm{pH}\left(\mathrm{pH}_{\mathrm{eq}}\right)$ was recorded.

\subsubsection{Equilibrium and kinetic studies}

Equilibrium evaluation was conducted in a batch mode using model Li solution (100 mL) in a beaker at varied HMO doses $(0.02 \mathrm{~g} / \mathrm{L}-0.20 \mathrm{~g} / \mathrm{L})$. The solution $\mathrm{pH}$ was maintained at an 
optimum value per $\mathrm{pH}$ evaluation (see Section 2.2.4.1). To attain equilibrium, the beakers were stirred $(120 \mathrm{rpm})$ using a flat shaker at room temperatures $\left(24 \pm 1{ }^{\circ} \mathrm{C}\right)$ for $24 \mathrm{~h}$. For the kinetic study, a fixed sorbent dose (selected based on equilibrium results) was used. Sample collection was carried out at 20 mins time intervals by up to 1440 mins. Equilibrium and kinetics a models used for this study is described in the supplementary material.

\subsubsection{Desorption and regeneration}

The reusability of HMO was tested with multiple adsorption and desorption cycles in batch mode. Adsorption was carried out using $\mathrm{HMO}$ at a dose of $0.1 \mathrm{~g} / \mathrm{L}$ with model Li solution. The used HMO was filtered from the working solution and dried at room temperature. Desorption was carried out using $\mathrm{HCl}$ based on the $\mathrm{Li} / \mathrm{H}$ exchange mechanism [18, 39]. Firstly, different $\mathrm{HCl}$ concentration was tested. Specifically Li-saturated $\mathrm{HMO}$ was placed in a beaker with 30 $\mathrm{mL}$ of $\mathrm{HCl}$ at different concentrations $(0.05 \mathrm{M}$ to $1.0 \mathrm{HCl})$ and kept suspended $(120 \mathrm{rpm})$ for $24 \mathrm{~h}$. Subsequently, upon identifying the optimum $\mathrm{HCl}$ concentration, multiple cycle of adsorption and desorption was carried out. The concentration of initial and final Li and dissolved Mn were measured using ICP-MS.

\subsection{Analysis}

\subsubsection{Solution concentration and characterization}

The ion concentrations of seawater and model solutions were determined by ICP-MS. The solution $\mathrm{pH}$ and total dissolved solids (TDS) were measured using a portable meter (model HQ40d HACH, US). The DOC content was measured using dual peak liquid chromatography with organic carbon detection (LC-OCD).

\subsubsection{Adsorbent and membrane characterization}


The new (virgin) and used DCMD membranes were characterized in terms of hydrophobicity (water contact angle) and morphology of its surfaces (upon drying). Membrane surface hydrophobicity was measured with water contact angle using goniometer (Theta Lite). Meanwhile, the morphology and ion contents of the membrane and HMO (unused and upon Li uptake) were examined by scanning electron microscope (SEM) operated at $15 \mathrm{kV}$ (Zeiss Supra 55VP Field Emission) combined with energy-dispersive spectroscopy (EDS) as described by our previous studies $[37,38]$. Changes on crystal structure of HMO was determined by X-ray powder diffraction (XRD) (Siemens D5000 diffractometer). XRD was operated with CuK alpha-radiation and sample stage that is rotating. Powder-form HMO (unused and upon Li uptake) were scanned at room temperature in the $2 \Theta$ angular range of $20-110^{\circ}$. HMO surface charges were detected using zetasizer analyser (Nano ZS Zen3600, Malvern, UK). HMO (0.05 $\mathrm{g} / \mathrm{L})$ was suspended and agitated (120rpm) in beakers containing $100 \mathrm{ml}$ of $\mathrm{LiCl}(5.0 \mathrm{mg} / \mathrm{L})$ in $\mathrm{pH}$ range of 3-11 for $24 \mathrm{~h}$. 


\section{Results and Discussion}

\subsection{Seawater chemical pretreatment}

The addition of oxalic acid enabled to minimize $\mathrm{Ca}$ content in seawater by forming insoluble calcium oxide precipitation (Eq. 1) [40] A byproduct of oxalic acid addition to seawater is $\mathrm{HCl}$ formation that contributed towards reducing the $\mathrm{pH}$ of seawater from $8.0 \pm 0.5$ to $3.0 \pm 0.5$.

$\mathrm{CaCl}_{2}(\mathrm{aq})+\mathrm{H}_{2} \mathrm{C}_{2} \mathrm{O}_{4}(\mathrm{aq})=\mathrm{CaC}_{2} \mathrm{O}_{4}(\mathrm{~s})+2 \mathrm{HCl}(\mathrm{aq})$

Higher Ca removal from seawater was achieved by increasing oxalic acid dosage from $0.1 \mathrm{~g} / \mathrm{L}$ to $3.0 \mathrm{~g} / \mathrm{L}$ (Fig. S1). From a dose of $2.5 \mathrm{~g} / \mathrm{L}$ oxalic acid onwards, $92-95 \%$ removal of Ca was achieved, indicating this to be the optimal dose. As such, $2.5 \mathrm{~g} / \mathrm{L}$ dose of oxalic acid was used for all further Ca removal experiments (Table 2).

At the same time, conventional caustic soda ash approach (addition of $\mathrm{Na}_{2} \mathrm{CO}_{3}$, combined with $\mathrm{NaOH}$ ) was also used for Ca removal from seawater [24]. In this approach, Ca was removed as $\mathrm{CaCO}_{3} . \mathrm{NaOH}$ was used to neutralize carbonic acid and to increase seawater $\mathrm{pH}$, as $\mathrm{Ca}$ precipitation is enhanced at higher $\mathrm{pH}$ ( $\mathrm{pH} 9$ and above). At $\mathrm{Na}_{2} \mathrm{CO}_{3}$ dose of $3.0 \mathrm{~g} / \mathrm{L}$ onwards, it was possible to achieve over 90\% Ca removal from seawater (Fig. S1, Table 2). However, the disadvantage of the caustic soda ash approach is that it resulted in an increase in Na content in alkaline condition (hydroxide residue). This apart, Ca removal occurred simultaneously with 26-30\% Mg removal. In this scenario, to attain pure $\mathrm{Ca}$, further purification steps will be required to separate $\mathrm{Mg}$ from $\mathrm{Ca}$. The separation of $\mathrm{Mg}$ from $\mathrm{Ca}$ can be challenging given both are divalent ions with similar chemical characteristics. 
Comparatively, the approach of using oxalic acid was beneficial for achieving selective $\mathrm{Ca}$ removal from seawater without simultaneous $\mathrm{Mg}$ removal. Further, the oxalic acid reduced $\mathrm{Na}$ concentration by about $23 \%$. Contrarily, the caustic soda ash method increased the Na content, invariably increasing the overall ion concentration in seawater. Nevertheless the addition of oxalic acid significantly increased the organic contents in seawater (DOC of $2.0 \pm 0.4 \mathrm{mg} / \mathrm{L}$ to $32.2 \pm 0.3 \mathrm{mg} / \mathrm{L})$. A simple granular activated carbon adsorption was used to remove the organic content. At a dose of $6.0 \mathrm{~g} / \mathrm{L}$ granular activated carbon, the organic content of oxalic acid treated seawater was reduced to $4.5 \pm 0.5 \mathrm{mg} / \mathrm{L}$ (Fig. S2). Given the toxicity of oxalic acid, granular activated carbon pretreatment could be used to remove the remaining/residue oxalic acid in concentrated seawater prior to its disposal if required. Comparatively, with the caustic soda ash approach, it is a challenge to reduce the salinity (dissolved sodium/salt contents) of concentrated seawater prior to disposal.

Table 2 Key parameters of original and pretreated seawater

\begin{tabular}{|c|c|c|c|c|c|c|c|c|}
\hline \multirow[t]{2}{*}{ Parameters } & \multirow[b]{2}{*}{ pH } & \multicolumn{7}{|c|}{ Concentration (mg/L) } \\
\hline & & DOC & $\mathbf{N a}$ & Mg & $\mathbf{C a}$ & $\mathbf{K}$ & $\mathbf{S r}$ & $\mathbf{L i}$ \\
\hline Original seawater & 8 & $1.6-2.0$ & 13642.38 & 1294.56 & 377.11 & 389.81 & 7.30 & 0.17 \\
\hline Pretreated seawater & & & & & & & & \\
\hline Oxalic acid and GAC & 3 & $4.0-5.0$ & 10473.44 & 1293.10 & 6.72 & 390.20 & 3.00 & 0.17 \\
\hline $\mathrm{Na}_{2} \mathrm{CO}_{3}$ and $\mathrm{NaOH}$ & 10 & $1.6-2.0$ & 14083.23 & 901.64 & 22.63 & 341.37 & 3.55 & 0.17 \\
\hline
\end{tabular}

\subsection{Performance of DCMD with seawater and pretreated seawater}

\subsubsection{Permeate flux and characteristics}

DCMD performance with seawater and pretreated seawater as feed solutions achieved similar initial permeate fluxes of $25.5 \pm 0.8 \mathrm{~L} / \mathrm{m}^{2} \mathrm{~h}(\mathrm{LMH})$ (Fig. 2). The similar initial permeate fluxes suggest that the initial variation of ion concentration in the feed solution minimally influenced 
the driving force, given that the same feed temperature difference was used for all experiments. Likewise, in a recent study, Kim et al [28] reported similar initial permeate fluxes with seawater as well as $\mathrm{Ca}$ and $\mathrm{Mg}$ reduced seawater. It is well established that vapour pressure (driving forces) in MD is minimally influenced by small variation in salt content (water activity) of the feed solution while its impact is apparent in highly supersaturated brines [30, 41]. This is because water activity only changes minimally (from 1.0 to 0.95 ) even when the molarity of $\mathrm{NaCl}$ is significantly varied (from $0.01 \mathrm{M}$ to $2.00 \mathrm{M}$ ). For all conditions, the permeate characteristics was of high quality throughout the experimental duration. Specifically, the final permeate solutions showed conductivity $(<20 \mu \mathrm{S} / \mathrm{cm})$ levels similar/lower to that of the initial permeate solutions and concentration of the major ions showed $98 \pm 2 \%$ ion rejection (Table SI).

In terms of permeate flux trend over volume concentration factor (VCF), DCMD operated with seawater and caustic soda ash pretreated seawater exhibited rapid decline of permeate fluxes (86-90\%) by VCF 3.0 onwards. Typically, seawater, in its original condition contain Ca in the range of $350-400 \mathrm{mg} / \mathrm{L}$. It is highly challenging for MD to treat original seawater due to the inevitable development of $\mathrm{Ca}$ based scaling in thermal condition, namely, $\mathrm{CaSO}_{4}$. As seawater is concentrated over time, $\mathrm{CaSO}_{4}$ scalant deposition onto the membrane resulted in permeate flux decline. This phenomena has been well established by a number of previous studies [19, 22, 42]. It is likely that $\mathrm{CaSO}_{4}$ deposition only occurred on the surface of the membrane and did not go through the pores. Therefore, permeate with high quality was still maintained throughout the experimental duration.

Given the dominant role of Ca scalant in reducing MD performance, minimizing Ca content in seawater, such as that of caustic soda ash softening, is therefore, expected to mitigate scaling 
issue and enhance MD performance towards concentrating seawater. In line with this, the results of this study show that seawater treated with caustic soda ash (containing reduced $\mathrm{Ca}$ ) enabled to achieve better performance to that of original seawater. Nevertheless, by VCF 4.0 (65-68\%), significant permeate flux decline occurred. This could be attributed to a number of factors. Firstly, caustic soda ash approach increased the $\mathrm{Na}$ content through the addition of sodium (hydroxide and carbonate) (as described in Section 3.1), invariably increasing the overall salinity and ion content of the feed solution. In MD, high salinity of the feed solution reduces vapour pressure, which in turn, reduces the driving force, resulting in permeate flux decline $[19,20,29,30]$. Secondly, caustic soda ash approach occur in alkaline condition with the addition of both hydroxide and carbonate. In thermal MD process, the residues of hydroxide and carbonate in alkaline condition, increases susceptibility towards inorganic scalant formation [31]. The formation of scalants that deposits onto the membrane, compromises the capacity of MD to further concentrate seawater.

On the other hand, DCMD effectively concentrated seawater treated with oxalic acid by up to VCF $7.8\left(88-91 \%\right.$ water recovery) with a gradual permeate flux decline from $25.5 \pm 0.8 \mathrm{~L} / \mathrm{m}^{2} \mathrm{~h}$ to $8.5 \pm 1.4 \mathrm{~L} / \mathrm{m}^{2} \mathrm{~h}$ (approximately $72 \%$ flux decline) (Fig. 2). The capacity of DCMD to concentrate oxalic acid treated seawater by up to VCF 7.0 could be attributed to the reduced initial ions in seawater, given that apart from 95\% Ca removal, oxalic acid also simultaneously removed $23 \%$ of $\mathrm{Na}$ (Table 2). This apart, the final ion mass balance of the DCMD concentrated seawater indicated reduction/losses of major ions (Table 3). Specifically, $\mathrm{Na}$ mass losses (26\%) occurred during the DCMD treatment. As the concentration of ions in oxalic acid treated seawater did not increase proportionally with volume concentration factor (VCF) during DCMD, it is likely that the negative effect of vapor pressure reduction with high salinity and concentration effect was minimized. This may have likely prevented the early and rapid 
flux decline trend that occurred with seawater and caustic soda ash treated seawater. Further, compared to the alkaline condition of caustic soda ash seawater ( $\mathrm{pH} 9.0 \pm 0.5$ ), addition of oxalic acid resulted in an acidic condition ( $\mathrm{pH} 3.0 \pm 0.5)$. The acidic condition was beneficial to delay induction of ion precipitation [36]. Specifically, the high $\mathrm{Na}$ mass losses indicated the occurrence of Na precipitation as it was concentrated in DCMD. However, it is likely that the acidic condition of the feed solution delayed ion induction and therefore, $\mathrm{Na}$ precipitation occurred only at the later duration of the DCMD operation. In line with this, gradual permeate flux decline occurred towards the final stages of the operation. Further, although precipitation of major ions occurred as seawater was concentrated/saturated, similar Li mass was maintained (Table 3). The insignificant losses of $\mathrm{Li}$ could be due to its high solubility and low concentration in seawater.

Overall, the results of this study highlight the suitability of oxalic acid as a seawater chemical pretreatment to minimize $\mathrm{Ca}$ scaling and effectively concentrate seawater in DCMD with insignificant losses of Li. In effect, this condition enabled to increase Li concentration in seawater by 7 times from $0.17 \mathrm{mg} / \mathrm{L}$ to $1.22 \mathrm{mg} / \mathrm{L}$, while achieving $86 \%$ water recovery (producing high quality fresh water).

\subsubsection{Membrane analysis}

Detailed membrane analysis (SEM-EDX) and contact angle evaluation was carried out to establish the effectiveness of oxalic acid pretreated seawater. Used membrane with seawater contained high Ca (Fig 3a). Further the hydrophobicity of the used membrane with seawater (water contact angle of $92.2 \pm 1.4^{\circ}$ ) was reduced by $40 \%$ compared to the virgin membrane (water contact angle of $138.6 \pm 2.7^{\circ}$ ). This verified the development of $\mathrm{CaSO}_{4}$ scaling that compromised the performance of DCMD with untreated seawater. Both used membranes with 
pretreated seawater of caustic soda ash and oxalic acid did not contain $\mathrm{Ca}$, indicating the effectiveness of both treatment approaches to minimise $\mathrm{Ca}$ content in seawater. However, significant presence of $\mathrm{Mg}$ and $\mathrm{Na}$ was detected on used membrane with caustic soda ash treated seawater (Fig 3b). The high $\mathrm{Mg}$ formation was most probably due to the addition of $\mathrm{NaOH}$ at $\mathrm{pH}$ above 9 that resulted in the formation of $\mathrm{MgOH}$ that adhered strongly onto the membranes. Further, higher $\mathrm{Na}$ concentration with the addition of $\mathrm{Na}_{2} \mathrm{CO}_{3}$ resulted in clear formation of $\mathrm{Na}$ on the membrane. The water contact angle of the used membrane with caustic soda ash treated seawater was $71.6 \pm 1.4^{\circ}$. Comparatively, the used DCMD membrane with oxalic acid treated membrane showed the presence of only high $\mathrm{Na}$. This was in line with the observation discussed in Section 3.2.1 on the flux decline at VCF 7.8 and the high Na mass losses with oxalic acid treated seawater (Table 3). It is important to note that visible colloids were formed with oxalic acid treated seawater and this is likely attributed to the high organic content. Further the water contact angle was also reduced to $87.7 \pm 0.7^{\circ}$. However, upon washing with citric acid, the colloids on the membrane was easily removed and the hydrophobicity (water contact angle of $132.4 \pm 3.8^{\circ}$ ) was comparatively similar to that of the virgin membrane (Fig. S3).

Table 3 Ion concentration and mass of pretreated seawater with oxalic acid with DCMD

\begin{tabular}{llllllll}
\hline $\begin{array}{l}\text { Oxalic acid } \\
\text { treated seawater }\end{array}$ & Ion content & $\mathbf{N a}$ & $\mathbf{M g}$ & $\mathbf{C a}$ & $\mathbf{K}$ & $\mathbf{S r}$ & $\mathbf{L i}$ \\
& & & & & & & \\
\hline \multirow{2}{*}{ Initial } & Concentration & $10473.44 \pm$ & $1293.18 \pm$ & $6.72 \pm$ & $390.20 \pm$ & $3.00 \pm$ & $0.17 \pm$ \\
& $(\mathrm{mg} / \mathrm{L})$ & 1.06 & 0.63 & 0.08 & 0.72 & 0.02 & 0.01 \\
\cline { 2 - 8 } & & $18852.19 \pm$ & $2327.72 \pm$ & $12.10 \pm$ & $702.36 \pm$ & $5.40 \pm$ & $0.31 \pm$ \\
$\mathbf{( 1 . 8 0} \mathbf{L})$ & Mass (mg) & 0.78 & 0.33 & 0.07 & 0.46 & 0.01 & 0.02 \\
& Concentration & $55339.73 \pm$ & $8498.63 \pm$ & $47.38 \pm$ & $2484.14 \pm$ & $15.90 \pm$ & $1.22 \pm$ \\
Final & $(\mathrm{mg} / \mathrm{L})$ & 1.21 & 0.77 & 0.11 & 0.62 & 0.06 & 0.02 \\
& & & & & & & \\
\hline
\end{tabular}




\begin{tabular}{llllllll}
\hline $\mathbf{( 0 . 2 5} \mathbf{L})$ & & $13890.27 \pm$ & $2133.16 \pm$ & $11.89 \pm$ & $623.52 \pm$ & $3.99 \pm$ & $0.31 \pm$ \\
& \multirow{2}{*}{ Mass (mg) } & 0.89 & 0.54 & 0.03 & 0.45 & 0.03 & 0.01 \\
\hline Mass losses (\%) & & 26.32 & 8.35 & 1.68 & 11.22 & 26.09 & - \\
\hline
\end{tabular}

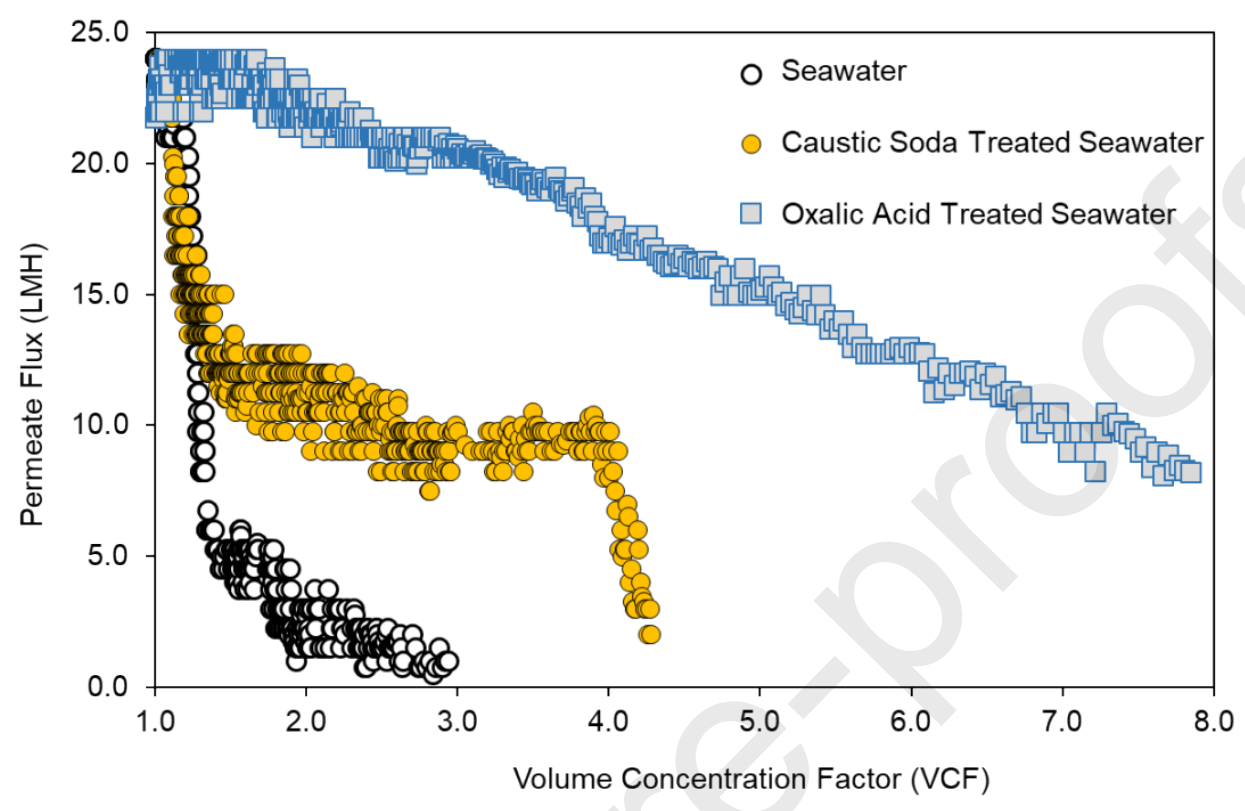

Fig. 2 DCMD permeate flux trend as a function of VCF with seawater and pretreated seawater using caustic soda ash and oxalic acid ( $V C F=$ volume ratio of initial to final feed solution, represents the degree of volume reduction of the feed solution). 

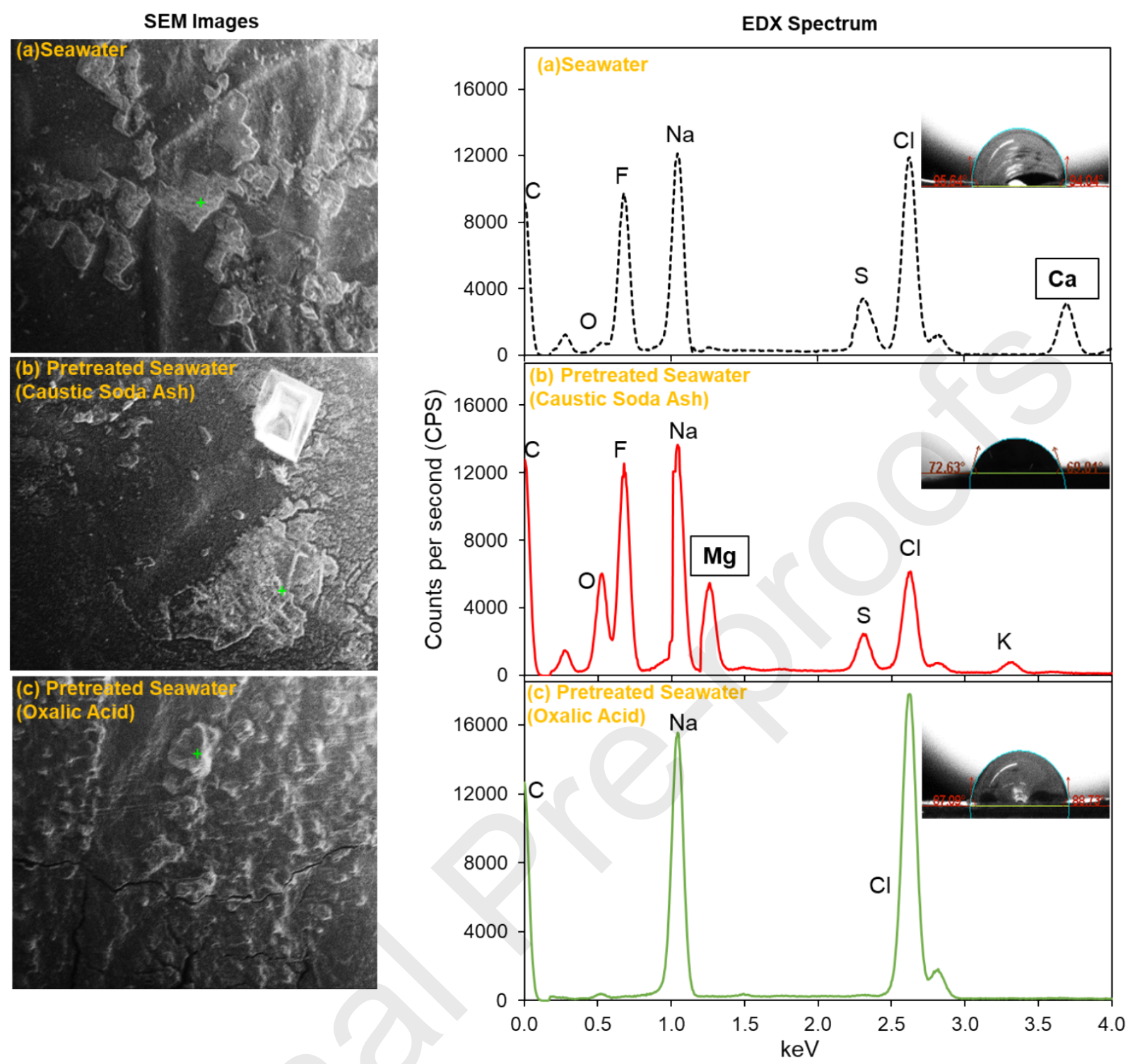

Fig. 3 SEM EDX of used DCMD membranes with seawater (VCF 3.0), caustic soda ash treated seawater (VCF 4.2) and oxalic acid treated seawater (VCF 7.8).

\subsection{Li extraction by HMO}

\subsubsection{HMO characteristics}

The XRD pattern of acid treated manganese oxide (HMO) and used ( $\mathrm{Li}$ extracted) HMO is presented in Fig. 4a. The XRD diffraction peaks show a similar trend, with relative peak shift and marginal changes to the intensities. The results were consistent with previous studies $[12$, 17, 18, 39, 43]. The slight peak shift towards higher diffraction angle in the used HMO 
compared to original/unused HMO could be attributed to delithiation of Li with H. For instance Xiao et al [43] reported on the crystal lattice shift (from 8.16 to $8.08 \AA$ ) of spinel-type LMO upon treatment with acid and associated this with the contraction of lattice due to $\mathrm{Li}$ to $\mathrm{H}$ ion exchange. Overall, the similar XRD diffraction pattern/intensity indicated the topotactic Li to $\mathrm{H}$ exchange during delithiation and the preservation of the cubic/spinel structure upon delithiation. Similar basic structure of the used and unused/original HMO established that Li extraction and replacement resulted in minimal damage to its structure, which implies the regenerative capacity of HMO.

In terms of morphology, the SEM images (Fig. 4b) showed that the HMO composed of dispersed particles with cluster forms of cubic like grains. Similar morphology and particle size distribution (average particle size of HMO and used HMO were $95.4 \pm 1.7 \mathrm{~nm}$ ) were observed between HMO and Li extracted HMO. The results were in line with previous studies $[17,18$, 44].

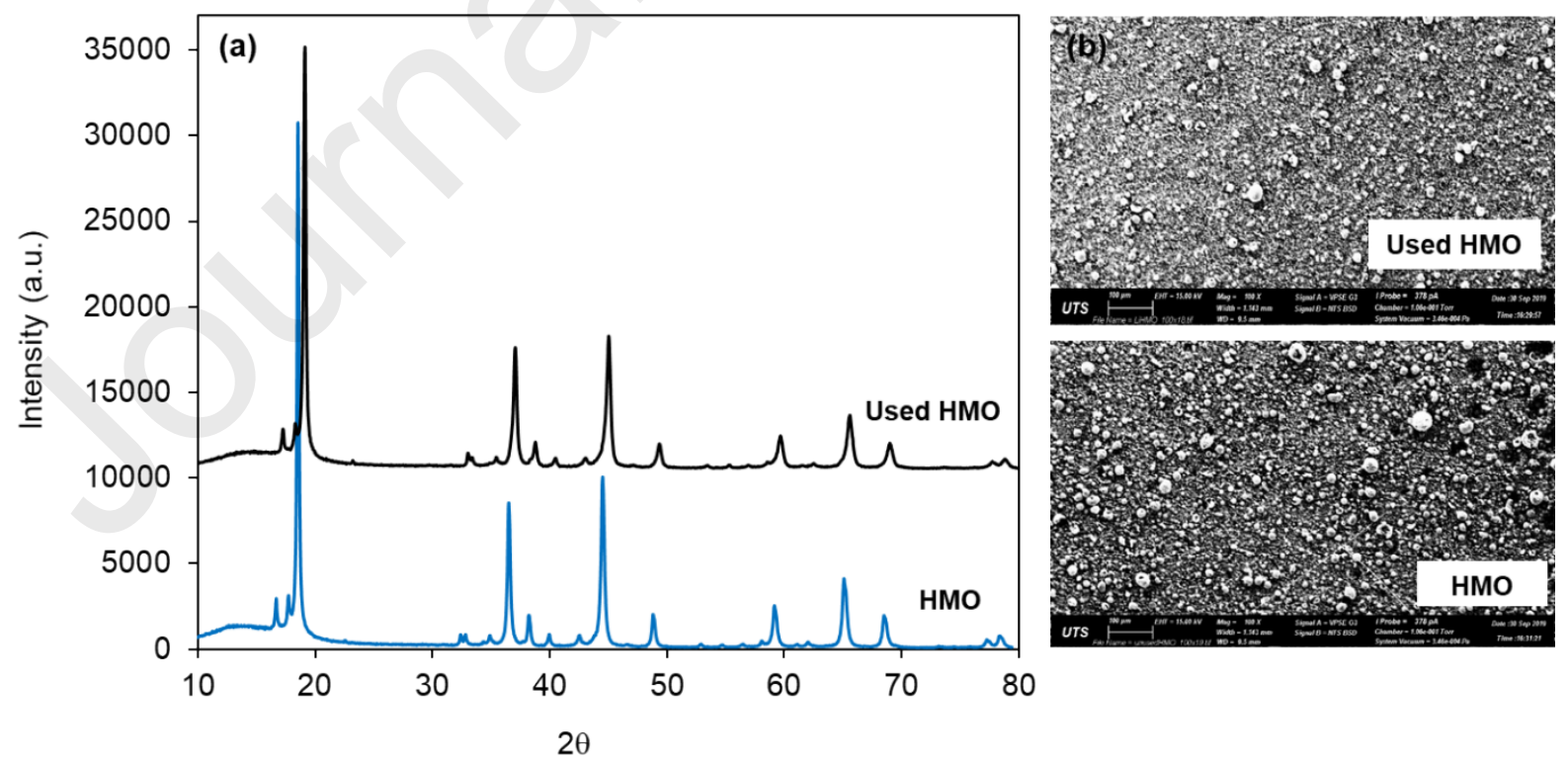

Fig. 4 Characteristics of HMO and Li extracted/used HMO (a) X-ray diffraction patterns of (b) SEM morphology images. 


\subsubsection{Li uptake by HMO}

\subsubsection{Influence of $\mathrm{pH}$ and surface zeta charge}

Li uptake increased from less than $2 \%$ by up to $98 \%$ as the solution $\mathrm{pH}$ was increased from 3 12 (Fig. 5). This indicated that the solution $\mathrm{pH}$ play a significant role in influencing Li uptake with HMO, as reported in previous studies $[11,18,39]$.

To gain a better understanding on the relationship of $\mathrm{pH}$ and $\mathrm{HMO}$ for $\mathrm{Li}$ uptake, the zeta potential (surface charge) of HMO was measured at varied $\mathrm{pH}$ ranges. The results showed that the surface charge of HMO became more negative with $\mathrm{pH}$ increment. Increased negative surface charge of an adsorbent enhances electrostatic adsorption (outer-sphere ion complexation) of positively charged ions [45]. Hence, it is likely that the high negative surface charge of HMO at higher $\mathrm{pH}$, attracts positively charged Li ion. In turn, higher Li uptake was achieved. At the same time, the presence of high hydroxide ions at $\mathrm{pH}$ above 6 provided a favourable deprotonation condition for the removal of $H$ from the ion sieve [11-13, 39]. This condition triggers the exchange of $\mathrm{H}$ from the adsorbent with $\mathrm{Li}$ from the solution. Correspondingly, it was observed that at $\mathrm{pH}$ above 6 , the initial $\mathrm{pH}$ value showed a reducing $\mathrm{pH}$ trend upon equilibrium, indicating the release of $\mathrm{H}$ from the adsorbent sites into the solution.

On the other hand, at lower $\mathrm{pH}$, the presence of high $\mathrm{H}$ ion in the solution create an unfavourable condition for deprotonation of $\mathrm{H}$ from the adsorbent [11-13, 39]. As a result, minimal vacant sites were made available for the exchange of $\mathrm{Li}$ with $\mathrm{H}$. This explains the low Li uptake (below 20\%) at $\mathrm{pH}$ below 6. 
It is also worth mentioning that at all $\mathrm{pH}$ ranges, only trace concentration of $\mathrm{Mn}$ was detected in the solution. This results suggest that Mn desorption from HMO was not influenced by $\mathrm{pH}$ change. Moreover, the desorbed concentration of Mn was insignificant compared to the amount of Li adsorbed. As such, Mn in HMO did not play a role in the Li adsorption mechanism. Further, minimal presence of Mn indicate the chemical stability of the adsorbent as observed by previous studies $[11,18,39]$.

Overall, the results establish that maximum $\mathrm{Li}$ uptake was obtained at $\mathrm{pH}_{\mathrm{eq}}$ of 11.6-11.8. However, at these $\mathrm{pH}$ ranges, precipitation of ions, namely, $\mathrm{Ca}$ and $\mathrm{Mg}$ is inevitable in mixed solution such as that in seawater. For this reason, all further experiments were carried out at $\mathrm{pH}_{\mathrm{eq}}$ of $11.0 \pm 0.5$ to achieve high Li uptake while ensuring minimal precipitation of divalent ions occur in seawater.

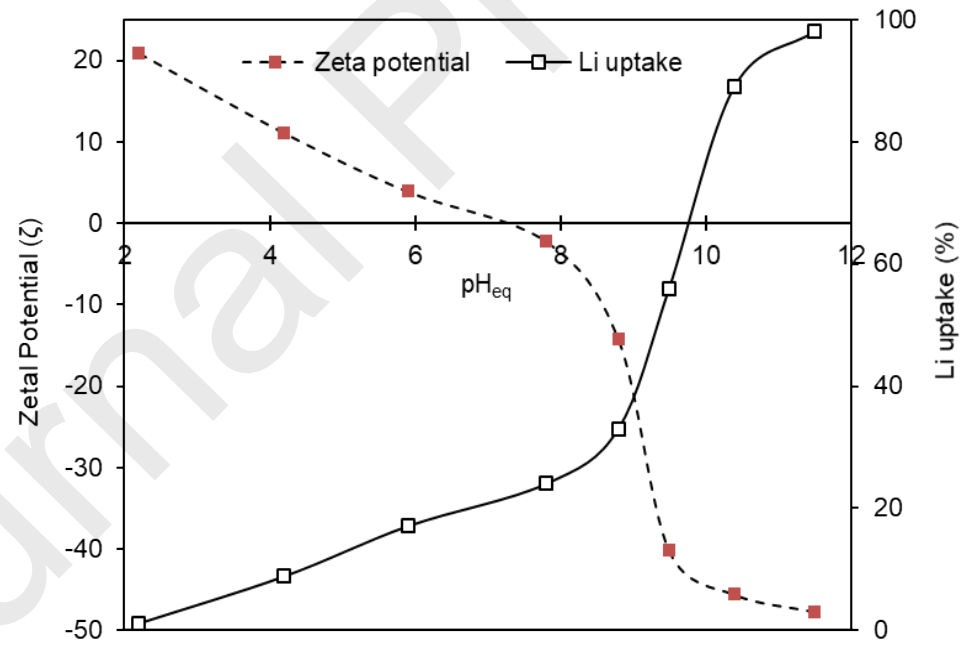

Fig. 5 Influence of pH on HMO surface zeta potential and Li uptake.

\subsubsection{Equilibrium adsorption}

\subsection{Isotherm}

Isotherm evaluation of HMO for Li uptake was carried out by varying the adsorbent dose $(0.05$ $\mathrm{g} / \mathrm{L}$ to $2.00 \mathrm{~g} / \mathrm{L})$ at $\mathrm{pH}_{\mathrm{eq}}$ of $11.0 \pm 0.5$ for $24 \mathrm{~h}$. The results showed that Li uptake capacity 
increased synonymously with equilibrium concentration before stabilising at maximum values

(Fig. 6a) The experimental data fitted well to both Langmuir and Freundlich isotherm models $\left(\mathrm{R}^{2}=0.94\right.$ - 0.98). Langmuir model fitting for Li uptake achieved a $\mathrm{Q}_{\max }$ of $17.8 \mathrm{mg} / \mathrm{g}$. The Langmuir isotherm model assumes saturated single-layer adsorption of the adsorbent surface. The model fitting indicated that $\mathrm{Li}$ adsorbed homogeneously onto HMO by forming a monolayer. Similar observations were reported by previous studies for Li uptake by HMO [18, 39, 46]. For instance, Park et al. [18] reported a Langmuir $\mathrm{Q}_{\max }$ of $15.1 \mathrm{mg} / \mathrm{g}$ for Li uptake with $\mathrm{HMO}$ at $\mathrm{pH} 11$ and equilibrium metal concentrations of 7-32 mg/L. Likewise, in a seawater solution spiked with high Li ion (30 mg/L), Hong et al. [46] achieved a $Q_{\max }$ of $18.0 \mathrm{mg} / \mathrm{g}$ using HMO powder. Higher adsorption capacity can be achieved by increasing the initial solution concentration and adsorption condition such as elevated $\mathrm{pH}$ and temperature. For instance, Shi et al. [39] achieved a high Li uptake of $27.2 \mathrm{mg} / \mathrm{g}$ with $\mathrm{HMO}$ by using a $\mathrm{pH}$ above 11 in salt brine containing high $\mathrm{Li}(300 \mathrm{mg} / \mathrm{L})$, at elevated temperature of $50{ }^{\circ} \mathrm{C}$.

\subsection{Kinetics}

The influence of time on Li uptake by HMO is displayed in Fig. 6b. Li uptake increased with time with a trend of rapid Li uptake at the initial stage $(0-7 \mathrm{~h})$ followed by a slow uptake till equilibrium was attained within 17-24 h. The experimental data was analysed using pseudo first and second order kinetic models (Table 4). The pseudo second order (PSO) model showed a better fitting $\left(\mathrm{R}^{2}=0.97-0.98\right)$, compared to pseudo first order (PFO) model. Better PSO representation of the experimental data suggest that Li uptake on HMO was predominantly a chemisorption reaction [45], by which, the Li concentration in the solution and the availability of sorption sides on HMO play important roles in influencing Li uptake. The chemisorption reaction description by PSO kinetic model is in line with the H-Li exchange mechanism by HMO as established by previous studies [12, 18]. 

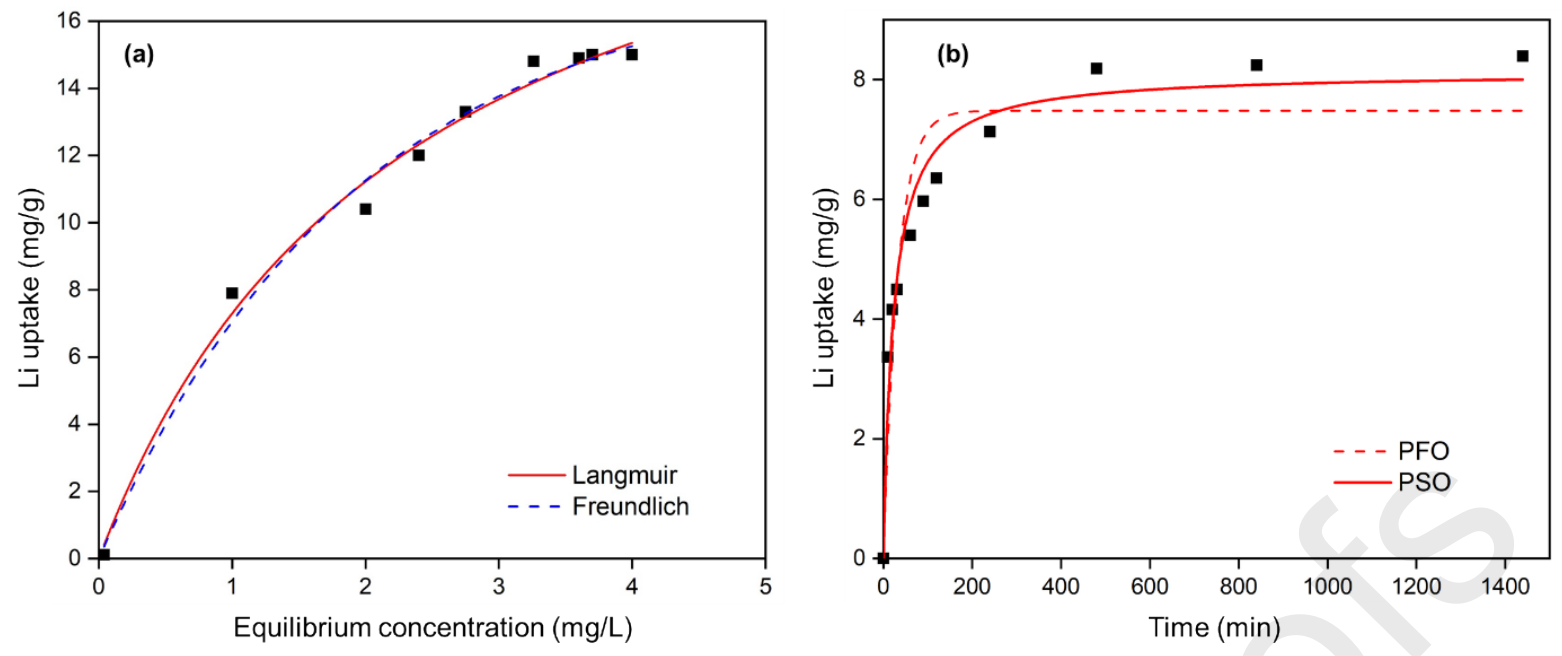

Fig 6. Equilibrium batch adsorption experiments with HMO for (a) Li uptake at different equilibrium concentrations descibed by Langmuir and Freundlich models $\left(\mathrm{C}_{\mathrm{o}}=5 \mathrm{mg} \mathrm{Li} / \mathrm{L}\right.$; $\mathrm{pH}_{\mathrm{eq}}=11.0 \pm 0.5$, time $=24 \mathrm{~h}$ ); and (b) Li uptake as a function of time descibed by pseudo first and second order kinetic models $\left(\mathrm{C}_{\mathrm{o}}=5 \mathrm{mg} \mathrm{Li} / \mathrm{L} ; \mathrm{pH}_{\mathrm{eq}}=11.0 \pm 0.5, \mathrm{HMO}\right.$ dose $\left.=0.5 \mathrm{~g} / \mathrm{L}\right)$.

Table 4 Equilibrium batch adsorption isotherm and kinetic model parameters for Li uptake with $\mathrm{HMO}$

\begin{tabular}{|c|c|c|c|c|c|c|}
\hline \multirow[t]{3}{*}{ Isotherm models } & & Langmui & & \multicolumn{3}{|c|}{ Freundlich } \\
\hline & $\mathrm{Q}_{\max }(\mathrm{mg} / \mathrm{g})$ & $\mathrm{K}_{\mathrm{L}}(\mathrm{L} / \mathrm{mg})$ & $\mathrm{R}^{2}$ & $\mathrm{n}$ & $\mathrm{K}_{\mathrm{F}}(\mathrm{mg} / \mathrm{g})$ & $\mathrm{R}^{2}$ \\
\hline & 17.76 & 1.13 & 0.98 & 2.25 & 8.34 & 0.96 \\
\hline \multirow[t]{3}{*}{ Kinetic models } & \multicolumn{3}{|c|}{ Pseudo-first order (PFO) } & \multicolumn{3}{|c|}{ Pseudo-second order (PSO) } \\
\hline & $\mathrm{q}_{\mathrm{e}}(\mathrm{mg} / \mathrm{g})$ & $\mathrm{K}_{1} \times 10^{-2}(\mathrm{n}$ & $\mathrm{R}^{2}$ & $\mathrm{q}_{\mathrm{e}}(\mathrm{n}$ & $\mathrm{K}_{2} \times 10^{-2}(\mathrm{r}$ & $\mathrm{R}^{2}$ \\
\hline & 5.00 & 0.11 & 0.81 & 8.54 & 0.41 & 0.99 \\
\hline
\end{tabular}

\subsubsection{Influence of ion competition}

The influence of ion competition was evaluated by comparing the capacity of HMO for achieving selective Li uptake in a single Li model solution and seawater (original and pretreated seawater). All experiments were carried out at $\mathrm{pH}_{\mathrm{eq}}$ of $11.0 \pm 0.5$ with the same $\mathrm{HMO}$ 
dose. Further, in order to compare the performance of HMO at the same initial concentration, seawater solutions were spiked with $5 \mathrm{mg} \mathrm{Li} / \mathrm{L}$ as that of the Li model solution.

Compared to the model Li solution, Li uptake capacity of HMO reduced by $44-46 \%$ in seawater (Fig. 7). Although Li uptake reduced in seawater, HMO was still able to maintain high Li selectivity, with minimal uptake of other major ions $(\mathrm{Na}, \mathrm{K}, \mathrm{Mg}$ and $\mathrm{Ca})$ present in high concentrations $(400-1700 \mathrm{mg} / \mathrm{L})$ to that of $\mathrm{Li}(5 \mathrm{mg} / \mathrm{L})$. Specifically, the concentration of $\mathrm{Na}$, and $\mathrm{K}$ remained similar before and after $\mathrm{HMO}$ adsorption, indicating that the uptake of these ions onto HMO did not occur simultaneously with Li uptake. Meanwhile, only a minimal $\mathrm{Ca}$ and $\mathrm{Mg}$ uptake (2-3\%) occurred simultaneously with Li uptake. The results of the study was in line with previous studies that evaluated the selective uptake of Li from mixed solution such as seawater, salt lake and geothermal brine. For instance, Park et al [18] used granular form polymer HMO and reported its capacity to maintain selective uptake of Li with minimal uptake of other major ions from seawater brine spiked with $15 \mathrm{mg} / \mathrm{L} \mathrm{Li}$. In another study, Xiao et al [43] reported on the high selective capacity of spinel form HMO towards Li extraction compared to $\mathrm{Na}, \mathrm{K}$ and $\mathrm{Ca}$ in salt lake brine. Likewise, Wang et al [14] reported on the capacity of chitosan granulated HMO to selectively extract Li from geothermal brine containing $\mathrm{Na}, \mathrm{K}$ and $\mathrm{Ca}$ in the background.

Given that the uptake of major ions were minimal, the significant reduction of Li uptake in seawater compared to single model Li solution could be attributed to non-specific surface adhesion of these ions on HMO. This may have resulted in surface competition with Li, which in turn, reduced Li uptake of HMO. Moreover, it is likely that $\mathrm{Na}, \mathrm{K}$ and Ca were unable to pass through the pores of the ion sieve HMO, attributed to the larger ionic radii of these ions compared to Li (Table 5); thus, they only attached to the surface of HMO. Comparatively, the 
ionic radii of $\mathrm{Li}(0.76 \AA)$ and $\mathrm{Mg}(0.72 \AA)$ are closely similar (Table 5). Further, apart from ionic radii, the high electronegativity of $\mathrm{Mg}$ compared to $\mathrm{Li}$ and other ions (Table 5) suggest the strong affinity of $\mathrm{Mg}$ to adhere onto the negative surface of HMO. Therefore, the presence of $\mathrm{Mg}$ could be the main ion competitor that reduced Li uptake in seawater with HMO. The strong $\mathrm{Mg}$ to Li ion competition has been highlighted in previous studies [14, 15, 43]. For instance, Gu et al [15] reported on the lower Li uptake of $\mathrm{H}$-form titanium oxide with salt lake brine compared to model Li solution and associated this with the presence of $\mathrm{Mg}$ that adhered onto the surface of the adsorbent.

In order to establish the influence of $\mathrm{Mg}, \mathrm{HMO}$ performance for $\mathrm{Li}$ uptake was evaluated with two types of pretreated seawater solution (oxalic acid $\mathrm{Ca}$ reduced seawater and divalent $(\mathrm{Ca}$ and $\mathrm{Mg}$ ) reduced seawater). The results showed that Li uptake by HMO only marginally improved with Ca reduced seawater compared to that of the original seawater (Fig. 7). These results indicated that the presence of $\mathrm{Ca}$ did not play a significant role in influencing Li uptake in seawater. This was in line with the theory discussed above on the inability of Ca to pass though the pores of the ion sieve due to its larger ionic size. On the other hand, the divalent $(\mathrm{Ca}$ and $\mathrm{Mg}$ ) reduced seawater achieved significantly high Li uptake, closely similar to that of the model Li solution. This results verified that the presence of $\mathrm{Mg}$ in seawater was the main ion that reduced Li uptake in seawater, compared to the other major ions $[15,47]$. However, in spite of the high $\mathrm{Mg}$ to $\mathrm{Li}$ concentration ratio, $\mathrm{Mg}$ uptake was minimal compared to Li uptake (as observed in original and Ca reduced seawater). The high hydration enthalpy of $\mathrm{Mg}$ (high energy required for $\mathrm{Mg}$ to attain dehydrated ionic condition) may have played a role in limiting its uptake onto HMO. 
Overall, these results indicated seawater with minimal of $\mathrm{Mg}$, provides a favourable condition for enhancing Li uptake by HMO in seawater. This necessitates Mg removal. In this study, Mg removal from seawater was achieved by adding $\mathrm{NaOH}$ as described in Section 2.2.2 (details presented in Supplementary Material, Fig. S4). The removal of Ca with oxalic acid followed by $\mathrm{Mg}$ removal with $\mathrm{NaOH}$ was beneficial in that it enables to produce firstly $\mathrm{Ca}$ followed by $\mathrm{Mg}$ from seawater as a byproduct. Further, the addition of $\mathrm{NaOH}$ for $\mathrm{Mg}$ removal at $\mathrm{pH}$ 11.0 \pm 0.5 was a suitable alkaline $\mathrm{pH}$ for Li uptake by HMO (as described in Section 3.3.2.1). Nevertheless, it is also important to mention that the addition of $\mathrm{NaOH}$ for $\mathrm{Mg}$ removal invariably increased $\mathrm{Na}$ content in seawater. As a result, a small amount of $\mathrm{Na}$ uptake occurred with $\mathrm{Li}$ uptake in divalent reduced seawater.

Table 5 Concentration of major ions in brine and its ionic characteristics.

\begin{tabular}{lllll}
\hline Ions & $\begin{array}{l}\text { Concentration in } \\
\text { seawater }(\mathrm{mg} / \mathrm{L})\end{array}$ & $\begin{array}{l}\text { Ionic radius, } \\
\mathrm{Na}\end{array}$ & $\begin{array}{l}\text { Electronegativity } \\
\text { Scale } \chi\end{array}$ & $\begin{array}{l}\text { Hydration enthalpy } \\
(\mathrm{kJ} / \mathrm{mol})\end{array}$ \\
$\mathbf{M g}$ & $\mathbf{1 , 2 0 0 - 1 , 3 0 0}$ & $\mathbf{0 . 7 2}$ & 0.93 & -405 \\
$\mathrm{Ca}$ & $370-410$ & 1.02 & $\mathbf{1 . 3 1}$ & $\mathbf{- 1 9 2 2}$ \\
$\mathrm{K}$ & $380-390$ & 1.38 & 1.00 & -1592 \\
$\mathbf{L i}$ & $\mathbf{0 . 1 2 - 0 . 1 8}$ & $\mathbf{0 . 7 6}$ & 0.82 & -312 \\
\hline
\end{tabular}




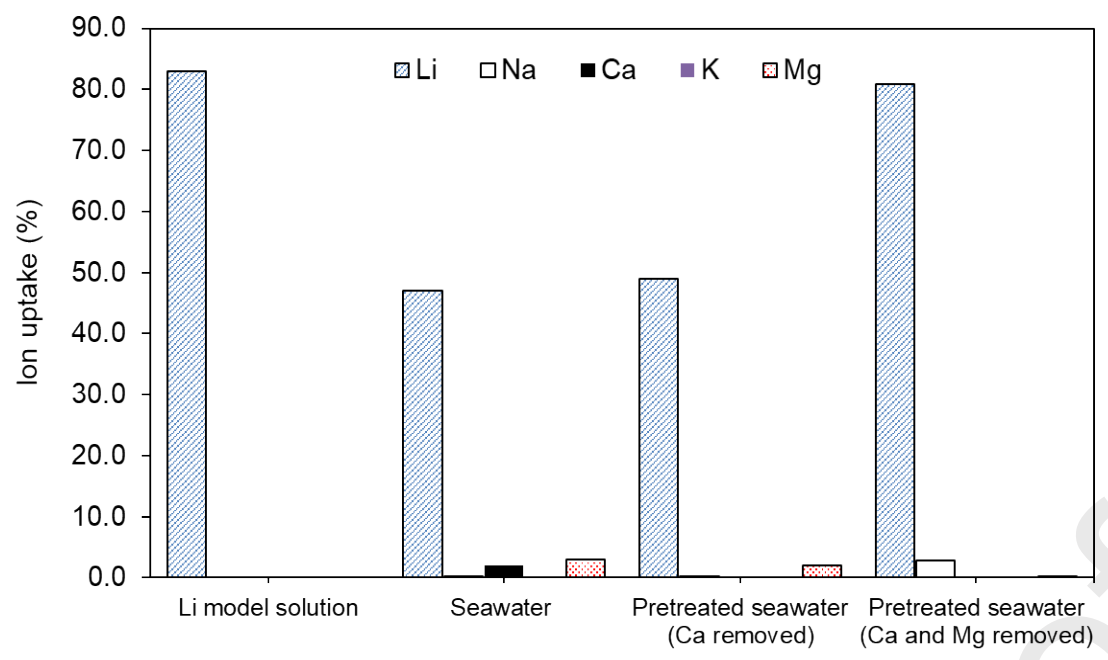

Fig. 7 Comparison of ion uptake by HMO in model Li solution, original and pretreated seawater spiked with $\mathrm{Li}\left(\mathrm{C}_{\mathrm{o}}=5 \mathrm{mg} \mathrm{Li} / \mathrm{L} ; \mathrm{pH}_{\mathrm{eq}}=11.0 \pm 0.5, \mathrm{HMO}\right.$ dose $\left.=0.5 \mathrm{~g} / \mathrm{L}\right) .($ Ca pretreated seawater solution using oxalic acid; Ca and Mg pretreated seawater using oxalic acid followed by $\mathrm{NaOH}$

\subsection{Desorption and regeneration}

In this study, $\mathrm{HCl}$ was used to desorb/extract Li and regenerate HMO. Different concentrations of $\mathrm{HCl}$ ranging from $0.05 \mathrm{M}$ to $1.00 \mathrm{M}$ was used to desorb $\mathrm{Li}$ from $\mathrm{HMO}$ (Fig. 8a). Close to $96.5 \pm 0.8 \%$ desorption was achieved with $0.1 \mathrm{M} \mathrm{HCl}$ onwards. Based on the results, $0.1 \mathrm{M} \mathrm{HCl}$ was selected to extract Li from HMO and for its regeneration.

The regenerative/reuse capacity of HMO was evaluated by multiple cycles of adsorbent and desorption (Fig. 8b). In the first cycle, higher Li desorption values than Li uptake occurred and this could be likely due to Li that was already present in the original HMO. In line with this, Mn dissolution was relatively higher in the first cycle. In the second cycle onwards slightly higher Li uptake occurred and this could be attributed to the higher availability of ion exchange sites due to full Li removal in the first cycle. In the subsequent cycles, Mn dissolution was relatively low and Li uptake was stable with a 7-11\% decline in Li uptake rate till the fifth 
cycle. The results established the feasible regenerative capacity of HMO and likewise, the XRD of the used HMO (Fig. 4) showed minimal damage to its structure. Similar results were reported by previous studies [39, 44]. For instance, Shi et al [39] analysed the XRD structure of HMO upon 10 cycles of regeneration and indicated its intact structure, establishing that HMO structure was not significantly affected by repeated cycles of adsorption and desorption. Nevertheless, it must be acknowledged that although regeneration in powder form HMO was possible in a batch study, mass losses will be inevitable in actual scenario. A suitable encapsulation of HMO will thus be necessary to retain its mass and enable a practical application in a dynamic filter column [18, 48].
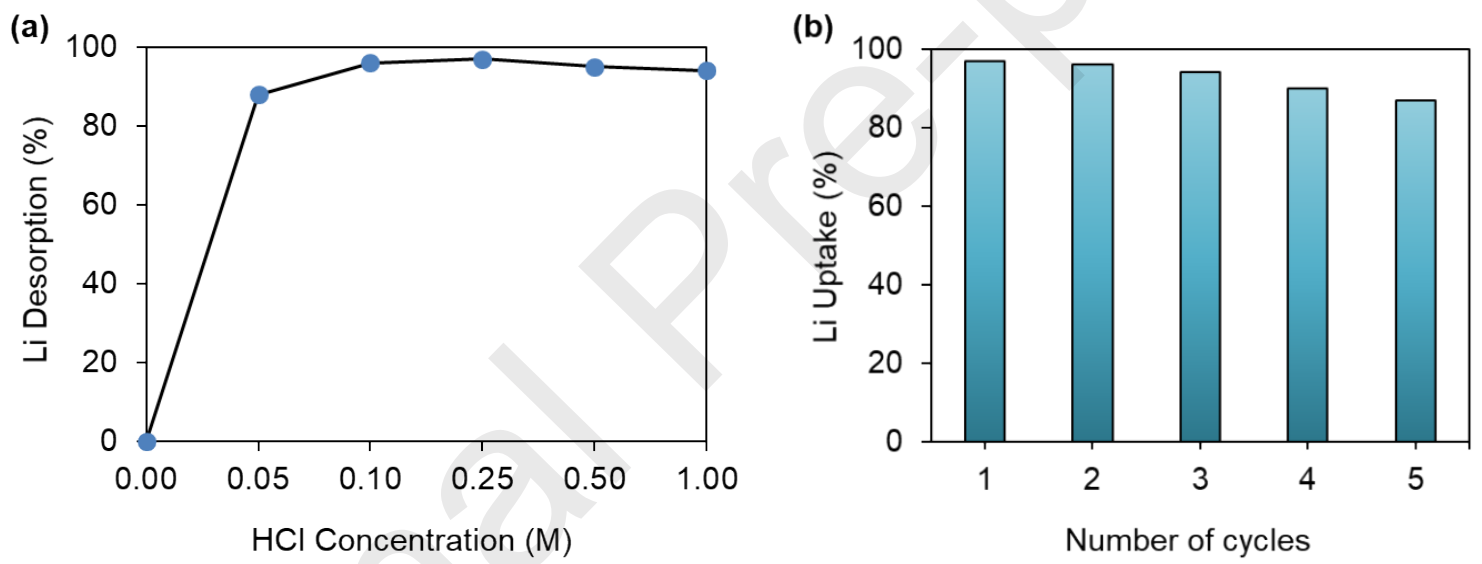

Fig. $8 \mathrm{HMO}$ regeneration capacity in terms of (a) $\mathrm{Li}$ desorption with $\mathrm{HCl}$ at varied concentration (b) Li uptake with 5 cycles of adsorption/desorption with $0.1 \mathrm{M} \mathrm{HCl}$. 


\section{Conclusion}

The focus of this study was to enhance the recovery of water and Li in seawater. For these reasons, the study evaluated (i) the suitability of oxalic acid as a seawater chemical softening treatment; (ii) water recovery rate of DCMD with pretreated seawater; and (iii) the capacity of HMO for selective Li uptake from concentrated seawater. The results of this study established that:

(i) Oxalic acid was highly suitable as a seawater chemical treatment for removing over $95 \%$ of $\mathrm{Ca}$ from seawater without any additional ion residues. Comparatively, caustic soda ash approach removed $\mathrm{Ca}$ simultaneously with $\mathrm{Mg}$, while increasing $\mathrm{Na}$ content in seawater;

(ii) The addition of oxalic acid into seawater significantly increased its organic content. A simple approach of granular activated carbon adsorption was effective to reduce the organic content in oxalic acid treated seawater by $84 \%$.

(ii) DCMD was able to concentrate oxalic acid treated seawater by up to volume concentration factor (VCF) of 7.5. This was attributed to reduced ion concentration and delayed induction of ion precipitation in acidic condition with oxalic acid treatment. Comparatively, DCMD operation with caustic soda ash treated seawater only achieve a VCF of 3.7 before experiencing flux decline.

(iii) DCMD process enabled to produce fresh water ( $86 \%$ water recovery) from oxalic acid treated seawater while successfully increasing Li concentration by $7-8$ times $(0.17 \mathrm{mg} / \mathrm{L}$ to $1.22 \mathrm{mg} / \mathrm{L})$.

(iv) HMO adsorbent exhibited favourable capacity for Li uptake attributed to selective $\mathrm{H} / \mathrm{Li}$ exchange in alkaline condition, enabling to achieve a Langmuir $\mathrm{Q}_{\max }$ of $17.8 \mathrm{mg} / \mathrm{g}$.

(v) The presence of $\mathrm{Mg}$ in seawater was the main ion competitor that reduced Li uptake in seawater, attributed to the closely similar ionic radii of $\mathrm{Li}$ and $\mathrm{Mg}$ and the high 
electronegativity of $\mathrm{Mg}$ compared to Li. Upon $\mathrm{Mg}$ removal, $\mathrm{HMO}$ was able to maintain high selective Li uptake from seawater.

(vi) It is not possible to achieve resource recovery by a single process. The treatment process in stages - pretreating, removing divalents and concentrating seawater, followed by adsorption by HMO, provides a favourable scenario for attaining high selective Li recovery from seawater as well as for recovering fresh water and other valuable products - Ca and Mg (Fig. 9).

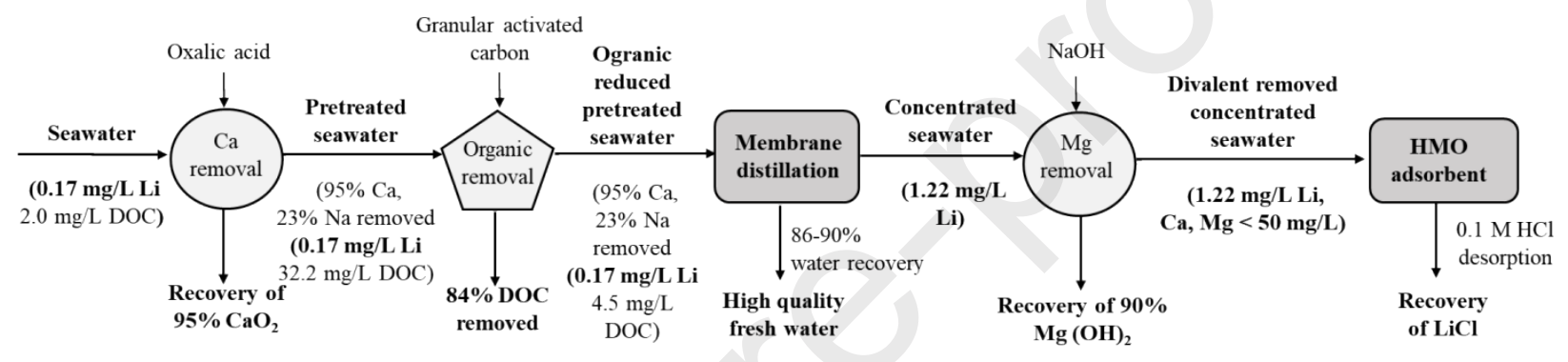

Fig. 9. Flow process used in this study for Li recovery from seawater along with the recovery of $\mathrm{Ca}, \mathrm{Mg}$ and fresh water

\section{Acknowledgements}

This work was funded by Australian Research Council Discovery Early Career Research Award (DE200100661). 


\section{References}

[1] V. Flexer, C.F. Baspineiro, C.I. Galli, Lithium recovery from brines: A vital raw material for green energies with a potential environmental impact in its mining and processing, Sci Total Environ, 639 (2018) 1188-1204.

[2] P. Loganathan, G. Naidu, S. Vigneswaran, Mining valuable minerals from seawater: a critical review, Environmental Science: Water Research \& Technology, 3 (2017) 37-53.

[3] C. Grosjean, P.H. Miranda, M. Perrin, P. Poggi, Assessment of world lithium resources and consequences of their geographic distribution on the expected development of the electric vehicle industry, Renewable and Sustainable Energy Reviews, 16 (2012) 1735-1744.

[4] P. Meshram, B.D. Pandey, T.R. Mankhand, Extraction of lithium from primary and secondary sources by pre-treatment, leaching and separation: A comprehensive review, Hydrometallurgy, 150 (2014) 192-208.

[5] G. Naidu, L. Tijing, M.A.H. Johir, H. Shon, S. Vigneswaran, Hybrid membrane distillation: Resource, nutrient and energy recovery, Journal of Membrane Science, 599 (2020) 117832.

[6] X. Li, Y. Mo, W. Qing, S. Shao, C.Y. Tang, J. Li, Membrane-based technologies for lithium recovery from water lithium resources: A review, Journal of Membrane Science, (2019) 117317.

[7] H.-Z. Zhang, Z.-L. Xu, H. Ding, Y.-J. Tang, Positively charged capillary nanofiltration membrane with high rejection for Mg2+ and Ca2+ and good separation for Mg2+ and Li+, Desalination, 420 (2017) 158166.

[8] G. Zante, M. Boltoeva, A. Masmoudi, R. Barillon, D. Trébouet, Lithium extraction from complex aqueous solutions using supported ionic liquid membranes, Journal of Membrane Science, 580 (2019) 62-76.

[9] R. Chitrakar, H. Kanoh, Y. Miyai, K. Ooi, Recovery of Lithium from Seawater Using Manganese Oxide Adsorbent (H1.6Mn1.6O4) Derived from Li1.6Mn1.6O4, Industrial \& Engineering Chemistry Research, 40 (2001) 2054-2058.

[10] S. Nishihama, K. Onishi, K. Yoshizuka, Selective Recovery Process of Lithium from Seawater Using Integrated Ion Exchange Methods, Solvent Extraction and Ion Exchange, 29 (2011) 421-431.

[11] T. Ryu, J. Shin, S.M. Ghoreishian, K.-S. Chung, Y.S. Huh, Recovery of lithium in seawater using a titanium intercalated lithium manganese oxide composite, Hydrometallurgy, 184 (2019) 22-28.

[12] L. Tian, W. Ma, M. Han, Adsorption behavior of Li+ onto nano-lithium ion sieve from hybrid magnesium/lithium manganese oxide, Chemical Engineering Journal, 156 (2010) 134-140.

[13] Q. Feng, Y. Miyai, H. Kanoh, K. Ooi, Lithium(1+) extraction/insertion with spinel-type lithium manganese oxides. Characterization of redox-type and ion-exchange-type sites, Langmuir, 8 (1992) 1861-1867.

[14] H. Wang, J. Cui, M. Li, Y. Guo, T. Deng, X. Yu, Selective recovery of lithium from geothermal water by EGDE cross-linked spherical CTS/LMO, Chemical Engineering Journal, 389 (2020) 124410.

[15] D. Gu, W. Sun, G. Han, Q. Cui, H. Wang, Lithium ion sieve synthesized via an improved solid state method and adsorption performance for West Taijinar Salt Lake brine, Chemical Engineering Journal, 350 (2018) 474-483.

[16] L. Liu, H. Zhang, Y. Zhang, D. Cao, X. Zhao, Lithium extraction from seawater by manganese oxide ion sieve $\mathrm{MnO} 2 \cdot 0.5 \mathrm{H} 2 \mathrm{O}$, Colloids and Surfaces A: Physicochemical and Engineering Aspects, 468 (2015) 280-284.

[17] H.-J. Hong, I.-S. Park, T. Ryu, J. Ryu, B.-G. Kim, K.-S. Chung, Granulation of Li1.33Mn1.67O4 (LMO) through the use of cross-linked chitosan for the effective recovery of Li+ from seawater, Chemical Engineering Journal, 234 (2013) 16-22.

[18] M.J. Park, G.M. Nisola, A.B. Beltran, R.E.C. Torrejos, J.G. Seo, S.-P. Lee, H. Kim, W.-J. Chung, Recyclable composite nanofiber adsorbent for Li+ recovery from seawater desalination retentate, Chemical Engineering Journal, 254 (2014) 73-81.

[19] J.P. Mericq, S. Laborie, C. Cabassud, Vacuum membrane distillation of seawater reverse osmosis brines, Water Res, 44 (2010) 5260-5273. 
[20] D. Winter, J. Koschikowski, M. Wieghaus, Desalination using membrane distillation: Experimental studies on full scale spiral wound modules, Journal of Membrane Science, 375 (2011) 104-112.

[21] D. González, J. Amigo, F. Suárez, Membrane distillation: Perspectives for sustainable and improved desalination, Renewable and Sustainable Energy Reviews, 80 (2017) 238-259.

[22] Y. Choi, G. Naidu, S. Jeong, S. Vigneswaran, S. Lee, R. Wang, A.G. Fane, Experimental comparison of submerged membrane distillation configurations for concentrated brine treatment, Desalination, 420 (2017) 54-62.

[23] J.-G. Lee, Y. Jang, L. Fortunato, S. Jeong, S. Lee, T. Leiknes, N. Ghaffour, An advanced online monitoring approach to study the scaling behavior in direct contact membrane distillation, Journal of Membrane Science, 546 (2018) 50-60.

[24] J.A. Sanmartino, M. Khayet, M.C. García-Payo, H. El-Bakouri, A. Riaza, Treatment of reverse osmosis brine by direct contact membrane distillation: Chemical pretreatment approach, Desalination, 420 (2017) 79-90.

[25] G.U. Semblante, J.Z. Lee, L.Y. Lee, S.L. Ong, H.Y. Ng, Brine pre-treatment technologies for zero liquid discharge systems, Desalination, 441 (2018) 96-111.

[26] M.H. Sorour, H.A. Hani, H.F. Shaalan, G.A. Al-Bazedi, Schemes for salt recovery from seawater and RO brines using chemical precipitation, Desalination and Water Treatment, 55 (2015) 2398-2407.

[27] X. Ji, E. Curcio, S. Al Obaidani, G. Di Profio, E. Fontananova, E. Drioli, Membrane distillationcrystallization of seawater reverse osmosis brines, Separation and Purification Technology, 71 (2010) 76-82.

[28] H.-W. Kim, T. Yun, S. Hong, S. Lee, S. Jeong, Retardation of wetting for membrane distillation by adjusting major components of seawater, Water Research, (2020) 115677.

[29] L. Eykens, I. Hitsov, K. De Sitter, C. Dotremont, L. Pinoy, I. Nopens, B. Van der Bruggen, Influence of membrane thickness and process conditions on direct contact membrane distillation at different salinities, Journal of Membrane Science, 498 (2016) 353-364.

[30] G. Guan, C. Yao, S. Lu, Y. Jiang, H. Yu, X. Yang, Sustainable operation of membrane distillation for hypersaline applications: Roles of brine salinity, membrane permeability and hydrodynamics, Desalination, 445 (2018) 123-137.

[31] D. Qu, J. Wang, L. Wang, D. Hou, Z. Luan, B. Wang, Integration of accelerated precipitation softening with membrane distillation for high-recovery desalination of primary reverse osmosis concentrate, Separation and Purification Technology, 67 (2009) 21-25.

[32] H.J. Lee, Y.J. Seo, J.W. Lee, Characterization of oxalic acid pretreatment on lignocellulosic biomass using oxalic acid recovered by electrodialysis, Bioresour Technol, 133 (2013) 87-91.

[33] O. Salmani Nuri, M. Irannajad, A. Mehdilo, Effect of surface dissolution by oxalic acid on flotation behavior of minerals, Journal of Materials Research and Technology, 8 (2019) 2336-2349.

[34] N. Chen, S. Tao, K. Xiao, S. Liang, J. Yang, L. Zhang, A one-step acidification strategy for sewage sludge dewatering with oxalic acid, Chemosphere, 238 (2020) 124598.

[35] E.P. Knoshaug, T. Dong, R. Spiller, N. Nagle, P.T. Pienkos, Pretreatment and fermentation of saltwater grown algal biomass as a feedstock for biofuels and high-value biochemicals, Algal Research, 36 (2018) 239-248.

[36] M. Gryta, Desalination of thermally softened water by membrane distillation process, Desalination, 257 (2010) 30-35.

[37] G. Naidu, S. Jeong, Y. Choi, S. Vigneswaran, Membrane distillation for wastewater reverse osmosis concentrate treatment with water reuse potential, Journal of Membrane Science, 524 (2017) 565-575.

[38] E.H.C. Castillo, N. Thomas, O. Al-Ketan, R. Rowshan, R.K. Abu Al-Rub, L.D. Nghiem, S. Vigneswaran, H.A. Arafat, G. Naidu, 3D printed spacers for organic fouling mitigation in membrane distillation, Journal of Membrane Science, 581 (2019) 331-343.

[39] X. Shi, D. Zhou, Z. Zhang, L. Yu, H. Xu, B. Chen, X. Yang, Synthesis and properties of Li1.6Mn1.604 and its adsorption application, Hydrometallurgy, 110 (2011) 99-106.

[40] G.A. Moldoveanu, V.G. Papangelakis, Strategies for calcium sulphate scale control in hydrometallurgical processes at $80^{\circ} \mathrm{C}$, Hydrometallurgy, 157 (2015) 133-139. 
[41] I. Hitsov, T. Maere, K. De Sitter, C. Dotremont, I. Nopens, Modelling approaches in membrane distillation: A critical review, Separation and Purification Technology, 142 (2015) 48-64.

[42] G. Naidu, S. Jeong, S. Vigneswaran, Interaction of humic substances on fouling in membrane distillation for seawater desalination, Chemical Engineering Journal, 262 (2015) 946-957.

[43] J. Xiao, X. Nie, S. Sun, X. Song, P. Li, J. Yu, Lithium ion adsorption-desorption properties on spinel Li4Mn5O12 and pH-dependent ion-exchange model, Advanced Powder Technology, 26 (2015) 589594.

[44] F. Ohashi, Y. Tai, Lithium adsorption from natural brine using surface-modified manganese oxide adsorbents, Materials Letters, 251 (2019) 214-217.

[45] G. Naidu, T. Nur, P. Loganathan, J. Kandasamy, S. Vigneswaran, Selective sorption of rubidium by potassium cobalt hexacyanoferrate, Separation and Purification Technology, 163 (2016) 238-246.

[46] H.-J. Hong, I.-S. Park, T. Ryu, B.-G. Kim, K.-S. Chung, Macroporous Hydrogen Manganese Oxide/Al2O3 for Effective Lithium Recovery from Seawater: Effects of the Macropores vs Mesopores, Industrial \& Engineering Chemistry Research, 58 (2019) 8342-8348.

[47] S. Wang, S. Zheng, Z. Wang, W. Cui, H. Zhang, L. Yang, Y. Zhang, P. Li, Superior lithium adsorption and required magnetic separation behavior of iron-doped lithium ion-sieves, Chemical Engineering Journal, 332 (2018) 160-168.

[48] G. Naidu, P. Loganathan, S. Jeong, M.A.H. Johir, V.H.P. To, J. Kandasamy, S. Vigneswaran, Rubidium extraction using an organic polymer encapsulated potassium copper hexacyanoferrate sorbent, Chemical Engineering Journal, 306 (2016) 31-42.

\section{DECLARATION OF INTEREST}

All authors declare that they have NO affiliations with or involvement in any organization or entity with any financial interest (such as honoraria; educational grants; participation in speakers' bureaus; membership, employment, consultancies, stock ownership, or other equity interest; and expert testimony or patent-licensing arrangements), or non-financial interest (such as personal or professional relationships, affiliations, knowledge or beliefs) in the subject matter or materials discussed in this manuscript.

\section{Graphic Abstract}

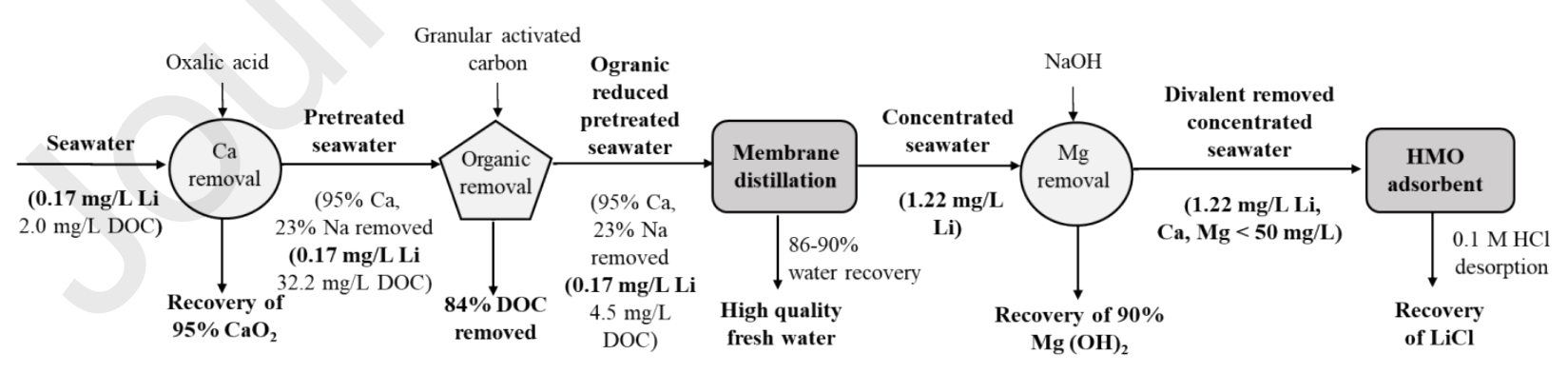

\section{Highlights}

- Oxalic acid efficiently removed $\mathrm{Ca}$ from seawater without any added ion residues.

- $\quad$ MD obtained 86-90\% water recovery and concentrated Li with oxalic acid seawater. 
- In seawater, Li uptake by $\mathrm{H}$-form manganese oxide sieve (HMO) was reduced due to $\mathrm{Mg}$.

- $\quad \mathrm{HMO}$ maintained high Li uptake in seawater upon Mg removal in alkaline condition.

- Seawater treatment in stages recovered water, $\mathrm{Li}$ and other resources - $\mathrm{Ca}$ and $\mathrm{Mg}$. 